Detection and characterization of singly deuterated silylene, SiHD, via optical spectroscopy

Damian L. Kokkin, Tongmei Ma, Timothy Steimle, and Trevor J. Sears

Citation: The Journal of Chemical Physics 144, 244304 (2016); doi: 10.1063/1.4954702

View online: http://dx.doi.org/10.1063/1.4954702

View Table of Contents: http://aip.scitation.org/toc/jcp/144/24

Published by the American Institute of Physics

Articles you may be interested in

Auxiliary-field quantum Monte Carlo calculations of the molybdenum dimer

The Journal of Chemical Physics 144, 244306 (2016); 10.1063/1.4954245

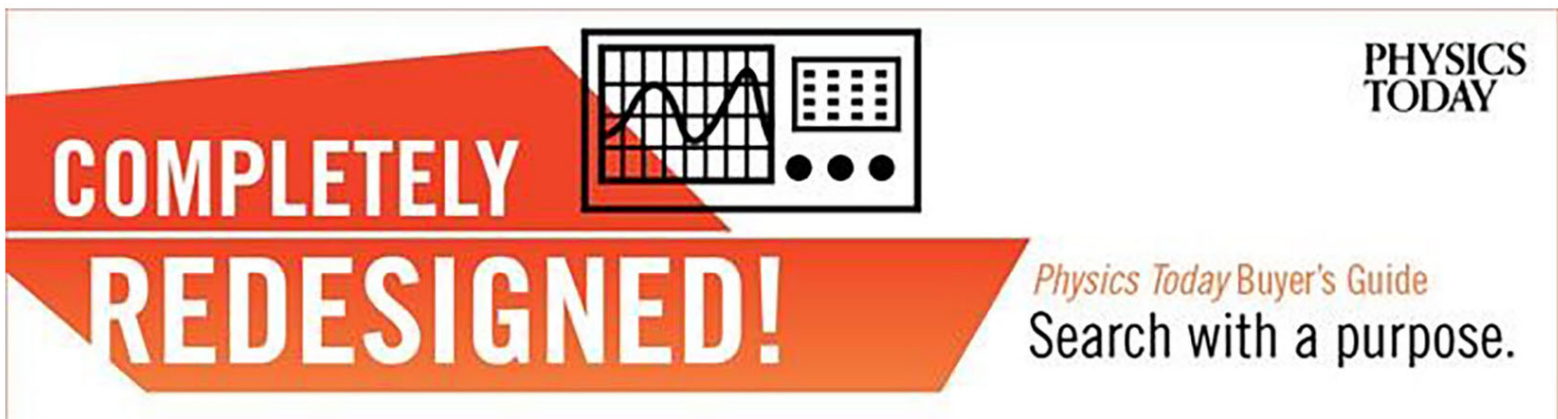




\title{
Detection and characterization of singly deuterated silylene, SiHD, via optical spectroscopy
}

\author{
Damian L. Kokkin, ${ }^{1}$ Tongmei Ma, ${ }^{1}$ Timothy Steimle, ${ }^{1, a)}$ and Trevor J. Sears ${ }^{2}$ \\ ${ }^{1}$ School of Molecular Sciences, Arizona State University, Tempe, Arizona 85287-1604, USA \\ ${ }^{2}$ Department of Chemistry, Brookhaven National Laboratory, Upton, New York 11973-5000, \\ USA and Chemistry Department, Stony Brook University, Stony Brook, New York 11794, USA
}

(Received 25 April 2016; accepted 13 June 2016; published online 27 June 2016)

\begin{abstract}
Singly deuterated silylene has been detected and characterized in the gas-phase using high-resolution, two-dimensional, optical spectroscopy. Rotationally resolved lines in the $0_{0}^{0} \tilde{X}^{1} A^{\prime} \rightarrow \widetilde{A}^{1} A^{\prime \prime}$ band are assigned to both $c$-type perpendicular transition and additional parallel, axis-switching induced bands. The extracted rotational constants were combined with those for $\mathrm{SiH}_{2}$ and $\mathrm{SiD}_{2}$ to determine an improved equilibrium bond length, $r_{\mathrm{SiH}}$, and bond angle, $\theta$, of $1.5137 \pm 0.0003 \AA$ and $92.04^{\circ} \pm 0.05^{\circ}$, and $1.4853 \pm 0.0005 \AA$ and $122.48^{\circ} \pm 0.08^{\circ}$ for the $\tilde{X}^{1} A^{\prime}(0,0,0)$ and $\tilde{A}^{1} A^{\prime \prime}(0,0,0)$ state respectively. The dispersed fluorescence consists of a long progression in the $\tilde{A}^{1} A^{\prime \prime}(0,0,0)$ $\rightarrow \tilde{X}^{1} A^{\prime}\left(0, v_{2}, 0\right)$ emission which was analyzed to produce vibrational parameters. A strong quantum level dependence of the rotationally resolved radiative decay curves is analyzed. Published by AIP Publishing. [http://dx.doi.org/10.1063/1.4954702]
\end{abstract}

\section{INTRODUCTION}

Understanding the observed electronic state energy ordering for silylene, $\mathrm{SiH}_{2}$, which is $\tilde{X}^{1} \mathrm{~A}_{1}<\tilde{a}^{3} \mathrm{~B}_{1}<\tilde{A}^{1} \mathrm{~B}_{1}$ $<\tilde{B}^{1} \mathrm{~A}_{1}$, relative to the energy ordering for methylene, $\mathrm{CH}_{2}$, which is $\tilde{X}^{3} \mathrm{~B}_{1}<\tilde{a}^{1} \mathrm{~A}_{1}<\tilde{b}^{1} \mathrm{~B}_{1}<\tilde{c}^{1} \mathrm{~A}_{1}$, has been of long standing theoretical interest, as has understanding the associated excited state unimolecular dynamics. Modelling the role of $\mathrm{SiH}_{2}$ in the fabrication of amorphous silicon thin films and polycrystalline silicon has also attracted significant interest. ${ }^{1-6}$ Motivated primarily by the desire to garner a fundamental understanding of the properties of this simplest of silicon containing polyatomic molecules, and in part by the desire to develop a real time, in situ $\mathrm{SiH}_{2}$ monitoring scheme, there have been numerous reported experimental ${ }^{7-28}$ and theoretical ${ }^{29-48}$ studies of gas-phase $\mathrm{SiH}_{2}$, and to a lesser extent $\mathrm{SiD}_{2}$. In addition, $\mathrm{SiH}_{2}$ is predicted to be abundant in circumstellar envelopes of carbon rich $\operatorname{stars}^{49}$ and has been tentatively identified ${ }^{50,51}$ via the detection of the $1_{11}-0_{00}$ pure rotational transition. In contrast to the extensive studies of the $\mathrm{SiH}_{2}$ and $\mathrm{SiD}_{2}$ isotopologues, the only previous experimental study of singly deuterated silylene (SiHD), which is the focus of this report, is the matrix isolated infrared spectroscopic study from which the fundamental vibrational frequencies of the $\tilde{X}^{1} \mathrm{~A}^{\prime}$ state were determined. ${ }^{52}$ The reduced symmetry of SiHD as compared to $\mathrm{SiH}_{2}$ and $\mathrm{SiD}_{2}$ causes the permanent electric dipole moment, $\vec{\mu}_{\text {el }}$, to have non-vanishing components on both the $a$ - and $b$-inertial axes. Consequently, the number of electric dipole allowed, pure rotational transitions, and the number of levels that strongly Stark tune are significantly more numerous. In addition, the reduced symmetry of SiHD

\footnotetext{
a) Author to whom correspondence should be addressed. Electronic mail: TSteimle@ASU.edu
}

causes the inertial axes of the $\tilde{A}^{1} \mathrm{~A}^{\prime \prime}$ state to be rotated relative to that of the $\tilde{X}^{1} \mathrm{~A}^{\prime}$ state, phenomena referred to as "axis-switching." 53-58 This leads to additional branch features in the electronic spectrum of SiHD relative to those for $\mathrm{SiH}_{2}$ and $\mathrm{SiD}_{2}$. This richer spectrum facilitates the extraction of structural parameters, investigation of dynamics, and provides additional possibilities for optical Stark spectroscopy.

A brief synopsis of the previous studies of $\mathrm{SiH}_{2}$ and $\mathrm{SiD}_{2}$ is warranted. The visible spectrum of $\mathrm{SiH}_{2}$ was first detected in the gas-phase in 1967 by Dubois, Herzberg, and Verma $^{7}$ using conventional visible absorption spectroscopy and rotationally analyzed soon thereafter. ${ }^{8}$ The spectrum was assigned to a progression in the $v_{2}^{\prime}$-bending mode of a $c$-type $\left(\Delta J=0, \pm 1, \Delta K_{\mathrm{a}}= \pm 1, \pm 3 \ldots \Delta K_{\mathrm{c}}=0, \pm 2, \ldots\right)$ $\tilde{X}^{1} \mathrm{~A}_{1} \rightarrow \tilde{A}^{1} \mathrm{~B}_{1}$ electronic transition. The visible spectrum exhibits numerous local perturbations because of strong interactions amongst the $\tilde{X}^{1} \mathrm{~A}_{1}, \tilde{A}^{1} \mathrm{~B}_{1}\left(\mathrm{E}_{0} \approx 1.9256 \mathrm{eV}^{20}\right)$, $\tilde{B}^{1} \mathrm{~A}_{1}\left(\mathrm{E}_{0} \approx 3.37 \mathrm{eV}^{45}\right)$, and $\tilde{a}^{3} \mathrm{~B}_{1}\left(\mathrm{E}_{0} \approx 0.9 \mathrm{eV}^{42}\right)$ states, which correlate to the ${ }^{1} \Sigma^{+},{ }^{3} \Sigma^{-}$, and ${ }^{1} \Delta$ states arising from the $\ldots \pi^{2}$ configuration in a linear structure. Laser induced fluorescence (LIF) detection of the visible bands was first reported in $1980 \mathrm{~s}^{10,11}$ and at about the same time by intracavity absorption. ${ }^{12}$ The sample was prepared by photolysis and microwave discharge under bulb conditions. The fluorescence lifetimes of $\tilde{A}^{1} \mathrm{~B}_{1}\left(0, v_{2}, 0\right)$ levels of a bulb sample were measured during this period both broad banded ${ }^{10}$ and at rotational resolution. ${ }^{10,13-15}$ The observed lifetimes varied widely depending upon the specific rovibronic level excited, and the decay curves were often biexponential. ${ }^{14}$ The behavior was interpreted as coupling of the $\tilde{A}^{1} \mathrm{~B}_{1}\left(0, v_{2}, 0\right)$ levels with background levels in the $\tilde{X}^{1} \mathrm{~A}_{1}$ and $\tilde{a}^{3} \mathrm{~B}_{1}$ states followed by predissociation. About the same time, the adiabatic ionization potential of the $\tilde{X}^{1} \mathrm{~A}_{1}$ and $\tilde{a}^{3} \mathrm{~B}_{1}$ states of $\mathrm{SiH}_{2}$ were experimentally determined ${ }^{16}$ and the infrared 
diode laser absorption spectrum of the $v_{2}$ band of the $\tilde{X}^{1} \mathrm{~A}_{1}$ state was recorded and analyzed. ${ }^{17}$

The first LIF detection of a supersonic free-jet expansion sample of $\mathrm{SiH}_{2}$ and $\mathrm{SiD}_{2}$ was performed by Fukashima et al. ${ }^{18}$ Both excitation and dispersed fluorescence spectra were measured for the $(0,0,0) \tilde{X}^{1} \mathrm{~A}_{1} \rightarrow\left(0, \mathrm{v}_{2}, 0\right) \tilde{A}^{1} \mathrm{~B}_{1}, \quad v_{2}$ $=0-6$, bands. It was proposed that the observed anomalous branch intensities were due to rotational and vibrational level-dependent nonradiative processes. The same group rerecorded the LIF excitation spectra of numerous bands of the $\tilde{X}^{1} \mathrm{~A}_{1} \rightarrow \tilde{A}^{1} \mathrm{~B}_{1}$ electronic transition of $\mathrm{SiD}_{2}$, which is much richer in features, at relatively high resolution $\left(0.03 \mathrm{~cm}^{-1}\right) .{ }^{19}$ The spectra were analyzed to produce a precise set of spectroscopic parameters for the $\tilde{X}^{1} \mathrm{~A}_{1}$ and $\tilde{A}^{1} \mathrm{~B}_{1}$ states. A similar LIF excitation and dispersed fluorescence study of a free-jet sample of $\mathrm{SiH}_{2}$, but at lower spectral resolution was reported by Ishikawa and Kajimoto. ${ }^{20}$ The developed LIF techniques were utilized for the detection of $\mathrm{SiH}_{2}$ in a plasma similar to those used for fabrication of amorphous silicon thin films. ${ }^{21-23}$

The most accurate spectroscopic parameters for $\mathrm{SiH}_{2}$ are from experiments performed nearly 20 years ago. In the case of the $\tilde{A}^{1} \mathrm{~B}_{1}$ state, they were derived from the analysis of cwintracavity laser absorption and cw-cavity ring down spectrum of the $0_{0}^{0}$ and $2_{0}^{2} \tilde{X}^{1} \mathrm{~A}_{1} \rightarrow \tilde{A}^{1} \mathrm{~B}_{1}$ bands. ${ }^{24,25}$ In those studies, rotational information up to $J=16, K_{a}=9$ was obtained from the analysis of Doppler limited spectra. A combined fit with the previous visible $e^{7,8}$ and infrared ${ }^{17}$ absorption measurements was performed. The $\tilde{X}^{1} \mathrm{~A}_{1}$ state parameters were derived from the analysis of infrared diode laser spectroscopic measurements. ${ }^{26}$ More recently, the stimulated emission pumping spectrum has also been recorded and interpreted ${ }^{27}$ to establish that the $(0,3,0) \quad \tilde{a}^{1} \mathrm{~B}_{1}$ state lies approximately $9640 \mathrm{~cm}^{-1}$ above $(0,0,0) \tilde{X}^{1} \mathrm{~A}_{1}$. In addition, an optical-optical double resonance technique was used to detect the $\tilde{B}^{1} \mathrm{~A}_{1}$ states of $\mathrm{SiH}_{2}$ and $\mathrm{SiD}_{2}{ }^{28}$ The spectra were interpreted as quasilinear behavior in the $\tilde{B}^{1} \mathrm{~A}_{1}$ state with a very small barrier $\left(\cong 125 \mathrm{~cm}^{-1}\right)$ to linearity.

Now turning to the theoretical studies, there have been numerous $a b$ initio predictions of the properties of $\mathrm{SiH}_{2}$, with particular emphasis on understanding the state ordering ${ }^{29-35,39-42,47}$ relative to that of $\mathrm{CH}_{2}$, to gain insight into the unimolecular dynamics, ${ }^{36,46,48}$ and aid in the interpretation of the spectra. ${ }^{37,43-46}$ In addition to these electronic structure prediction, Duxbury et al. ${ }^{38}$ reanalyzed the originally recorded $\tilde{X}^{1} \mathrm{~A}_{1} \rightarrow \tilde{A}^{1} \mathrm{~B}_{1}$ absorption spectra of $\mathrm{SiH}_{2}^{7,8}$ and rationalized the strong local perturbations and observed anomalous radiative lifetimes ${ }^{14,15}$ using a semi-quantitative model. That model simultaneously accounted for the combined effects of Renner-Teller coupling of the $\tilde{X}^{1} \mathrm{~A}_{1}$ and $\tilde{A}^{1} \mathrm{~B}_{1}$ states, direct spin-orbit coupling of the $\tilde{a}^{3} \mathrm{~B}_{1}$ and $\tilde{X}^{1} \mathrm{~A}_{1}$ states, and second order spin-orbit coupling of the $\tilde{a}^{3} \mathrm{~B}_{1}$ and $\tilde{A}^{1} \mathrm{~B}_{1}$ states. A more quantitative, theoretical-based analysis of the interacting $\tilde{X}^{1} \mathrm{~A}_{1}$ and $\tilde{A}^{1} \mathrm{~B}_{1}$ states of $\mathrm{SiH}_{2}$ and $\mathrm{SiD}_{2}$ was carried out by Yurchenko et al. ${ }^{43}$ In that study, ab initio calculations of the potential energy surfaces (PESs), the electric dipole moments, and the electric dipole transition moment surfaces for the $\tilde{X}^{1} \mathrm{~A}_{1}$ and $\tilde{A}^{1} \mathrm{~B}_{1}$ were performed. The PESs were used to calculate the rovibronic energies which were compared with experimental values and subsequently the PESs were modified to improve the agreement. Using these refined PESs for the $\tilde{X}^{1} \mathrm{~A}_{1}$ and $\tilde{A}^{1} \mathrm{~B}_{1}$ states, and accounting for the Renner-Teller coupling of these two states, the $\tilde{A}^{1} \mathrm{~B}_{1} \rightarrow \tilde{X}^{1} \mathrm{~A}_{1}$ emission spectrum was simulated. The agreement between the observed and calculated spectra was relatively poor, suggesting that accounting only for the Renner-Teller coupling and not spin-orbit interaction is insufficient. The same group used a similar approach to refine a predicted PES for the $\tilde{B}^{1} \mathrm{~A}_{1}$ state for $\mathrm{SiH}_{2}$ and $\mathrm{SiD}_{2}{ }^{44}$ The optimized PESs were used to calculate the $\tilde{B}^{1} \mathrm{~A}_{1}$ term values and predict the rotation-vibration spectrum associated with the $\tilde{B}^{1} \mathrm{~A}_{1}$ state.

At about the same time, in an attempt to understand the $\tilde{X}^{1} \mathrm{~A}_{1} \rightarrow \tilde{A}^{1} \mathrm{~B}_{1} \rightarrow \tilde{B}^{1} \mathrm{~A}_{1}$ photoexcitation, the vibrational energies for the $\tilde{X}^{1} \mathrm{~A}_{1}, \tilde{A}^{1} \mathrm{~B}_{1}$, and $\tilde{B}^{1} \mathrm{~A}_{1}$ states of $\mathrm{SiH}_{2}$ and $\mathrm{SiD}_{2}$ were calculated, based on generated global PESs. ${ }^{45}$ The vibrational levels, Franck-Condon factors (FCFs), and related transition probabilities were calculated. RennerTeller effects were ignored. In a subsequent paper, ${ }^{46}$ the same group investigated excited-state dynamics and the vibrational state dependence of the dissociations following the $\tilde{A}^{1} \mathrm{~B}_{1} \rightarrow \tilde{B}^{1} \mathrm{~A}_{1}$ photoexcitation using three dimensional wave packet propagation methods. As part of that study, the vibronic energies for the $\tilde{X}^{1} \mathrm{~A}^{\prime}, \tilde{A}^{1} \mathrm{~A}^{\prime \prime}$, and $\tilde{B}^{1} \mathrm{~A}^{\prime}$ states of SiHD were also calculated. Interestingly, the photon energy dependence of the total photodissociation cross section was predicted to be fairly similar for $\mathrm{SiH}_{2}$ and $\mathrm{SiD}_{2}$, but very different from that predicted for SiHD. This marked difference in the photodissociation cross section was attributed to subtle difference in PESs for the $\tilde{A}$ and $\tilde{B}$ states and differences in vibrational wavefunctions. This is presumably associated with the fact that SiHD has $C_{S}$-symmetry compared to the $C_{2 v}$-symmetry of $\mathrm{SiH}_{2}$ and $\mathrm{SiD}_{2}$.

Recently $\mathrm{SiH}_{2}$ was selected as a venue for evaluation of the performance of time independent nonadiabatic transition state theory (NA-TST) relative to that of the more computationally demanding, quantum-based surface hopping method in an attempt to model spin-orbit induced intersystem crossing dynamics. ${ }^{48}$ The $\tilde{X}^{1} \mathrm{~A}_{1} / \tilde{a}^{3} \mathrm{~B}_{1}$ system of $\mathrm{SiH}_{2}$ was viewed as better suited for model studies of nonadiabatic dynamics of states involving different multiplicities than the $\tilde{X}^{3} \mathrm{~B}_{1} / \tilde{a}^{1} \mathrm{~A}_{1}$ system of $\mathrm{CH}_{2}$, due to the larger spin-orbit coupling. The NA-TST and surface hopping methods predicted grossly different values for the $\tilde{X}^{1} \mathrm{~A}_{1} / \tilde{a}^{3} \mathrm{~B}_{1}$ intersystem crossing rates of $\mathrm{SiH}_{2}$. There is no experimental information for the $\tilde{X}^{1} \mathrm{~A}_{1} / \tilde{a}^{3} \mathrm{~B}_{1}$ intersystem crossing, limiting assessment of the two methods employed. The effects of lowering the symmetry to that of SiHD were not considered, but should be large.

Here we report on the first LIF spectroscopic measurements of SiHD. Excitation and dispersed fluorescence spectroscopy and fluorescence decay curve measurements of the $0_{0}^{0} \tilde{X}^{1} \mathrm{~A}^{\prime} \rightarrow \tilde{A}^{1} \mathrm{~A}^{\prime \prime}$ band near $643 \mathrm{~nm}$ have been performed. The $0_{0}^{0} \tilde{X}^{1} \mathrm{~A}^{\prime} \rightarrow \tilde{A}^{1} \mathrm{~A}^{\prime \prime}$ band was selected instead of the more intense $2_{0}^{2} \tilde{X}^{1} \mathrm{~A}^{\prime} \rightarrow \tilde{A}^{1} \mathrm{~A}^{\prime \prime}$ band near $580 \mathrm{~nm}$ in the anticipation of fewer local perturbations resulting in a richer spectrum due to a lower predissociation rate. 


\section{EXPERIMENTAL}

Singly deuterated silylene (SiHD) was generated via a supersonic, pulsed, d.c. discharge through a mixture of silane $\left(\mathrm{SiH}_{4}\right)(\sim 2 \%)$, deuterium $\left(\mathrm{D}_{2}\right)(\sim 5 \%)$, and argon $(\sim 93 \%)$ at a backing pressure of approximately 400 PSI and operated at $20 \mathrm{~Hz}$. The supersonic d.c. discharge source has been previously described. ${ }^{59}$ The free-jet expansion was probed approximately $10 \mathrm{~cm}$ downstream. Four types of experiments were performed: (a) two dimensional (2D), medium resolution, excitation spectroscopy of the $0_{0}^{0} \tilde{X}^{1} \mathrm{~A}^{\prime}$ $\rightarrow \tilde{A}^{1} \mathrm{~A}^{\prime \prime}$ band of $\mathrm{SiHD}$, and corresponding bands of $\mathrm{SiH}_{2}$ and $\mathrm{SiD}_{2}$ using a Nd:YAG pumped pulsed dye laser; (b) two dimensional (2D), high resolution, excitation spectroscopy of the $0_{0}^{0} \tilde{X}^{1} \mathrm{~A}^{\prime} \rightarrow \tilde{A}^{1} \mathrm{~A}^{\prime \prime}$ band of SiHD using a single frequency cw-dye laser; (c) dispersed fluorescence (DF) resulting from the $0_{0}^{0} \tilde{X}^{1} \mathrm{~A}^{\prime} \rightarrow \tilde{A}^{1} \mathrm{~A}^{\prime \prime}$ excitation; and (d) rovibronic resolved fluorescent lifetime measurements. The two dimensional (2D) method ${ }^{60,61}$ used to record the excitation spectra was previously described. ${ }^{62}$ Briefly, a $75 \mathrm{~nm}$ wide spectral window in the dispersed fluorescence is simultaneously monitored using a cooled, gated, intensified CCD detector attached to a $2 / 3 \mathrm{~m}$ monochromator. The CCD detector gate for the pulsed dye laser 2D spectral measurements was typically set to a 1 $\mu$ s width and delayed $20 \mathrm{~ns}$ from the laser. The CCD detector gate for the $\mathrm{cw}$-dye laser $2 \mathrm{D}$ measurments was typically set to $30 \mu \mathrm{s}$, which approximately corresponds to the transit time of the pulsed free-jet expansion through the viewing region of the LIF collection optics. The central wavelength of the $75 \mathrm{~nm}$ wide monochromator spectral window was usually selected to look at the off-resonance $\tilde{A}^{1} \mathrm{~A}^{\prime \prime}(000) \rightarrow \tilde{X}^{1} \mathrm{~A}^{\prime}(010)$ emission and was tracked with the wavelength of the laser excitation source. The entrance slit width of the monochromator was set to produce a spectral resolution of approximately $\pm 2 \mathrm{~nm}$ for the DF. Typically, in the $2 \mathrm{D}$ measurements, 30 free-jet expansion pulses were averaged at a given laser excitation wavelength. A calibrated commercial wavemeter was used to determine the absolute wavenumber of the pulsed dye laser. The transition wavenumbers of the high-resolution 2D spectra were accurately determined by simultaneously measuring the sub-Doppler spectrum of iodine. ${ }^{63}$ The pulsed or cw-dye laser 2D spectra were subsequently processed to produce excitation spectra by vertically summing of the pixels of the $\mathrm{CCD}$ detector along a horizontal slice (e.g., the $\tilde{A}^{1} \mathrm{~A}^{\prime \prime}(000) \rightarrow \tilde{X}^{1} \mathrm{~A}^{\prime}(010)$ emission).

DF spectra having higher resolution than those associated with the 2D measurments were recorded using the software provided with the camera and pulsed dye laser excitation. In these measurements, the entrance slit on the monochromator was narrowed to produce a resulting spectral resolution of approximately $\pm 0.7 \mathrm{~nm}$. The DF signal at a given emission wavelength was obtained from vertical binning of the intensified CCD detector. Typically in this mode of operation, 10000 averages were taken for each $75 \mathrm{~nm}$ monochromator transmission window. The multiple $75-\mathrm{nm}$ wide, one-dimensional arrays of intensity versus dispersed fluorescence wavelength were spliced together, and adjusted for wavelength variation of sensitivity, to produce the DF spectra. Wavelength calibration of the DF spectra was achieved by recording the emission of an argon pen lamp. The calibration lines also facilitated the splicing together of the 75-nm-wide segments.

The fluorescence decay curves were measured by tuning the laser wavelength to be resonant with a particular feature of the excitation spectra and recording the DF spectrum at variable time delays from the pulsed laser. The gate for the CCD detector was set to a large value (approximately $1 \mu \mathrm{s}$ ) and the time delay from the laser excitation stepped in 20 ns increments to produce a series of DF spectra. The
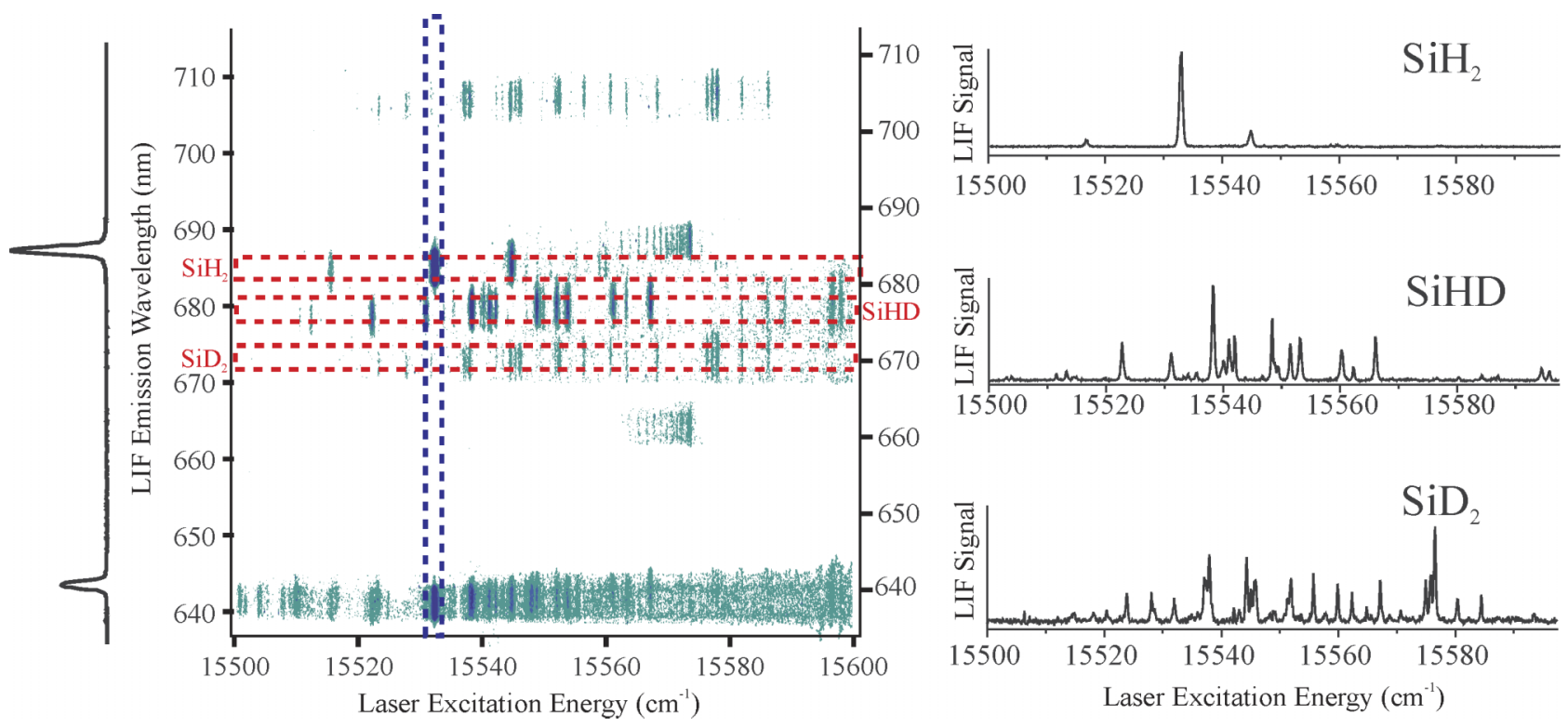

FIG. 1. Center: The pulsed dye laser, two dimensional (2D) spectrum of silylene radicals generated in a $\mathrm{SiH}_{4}+\mathrm{D}_{2} \mathrm{supersonic}$ d.c. discharge expansion. Right: The off-resonance detected laser excitation spectra obtained from the vertical integration of the intensities of the three horizontal slices marked by the dashed red rectangles. Left: The dispersed fluorescence (DF) spectrum resulting from laser excitation of ${ }^{\mathrm{p}} \mathrm{P}_{1}(1) 0_{0}^{0} \tilde{X}^{1} \mathrm{~A}_{1} \rightarrow \tilde{A}^{1} \mathrm{~B}_{1}$ transition of $\mathrm{SiH} \mathrm{H}_{2}$ at $15532 \mathrm{~cm}{ }^{-1}$. The spectrum was obtained from the horizontal integration of the intensities of the vertical slice marked by the dashed blue rectangle. 

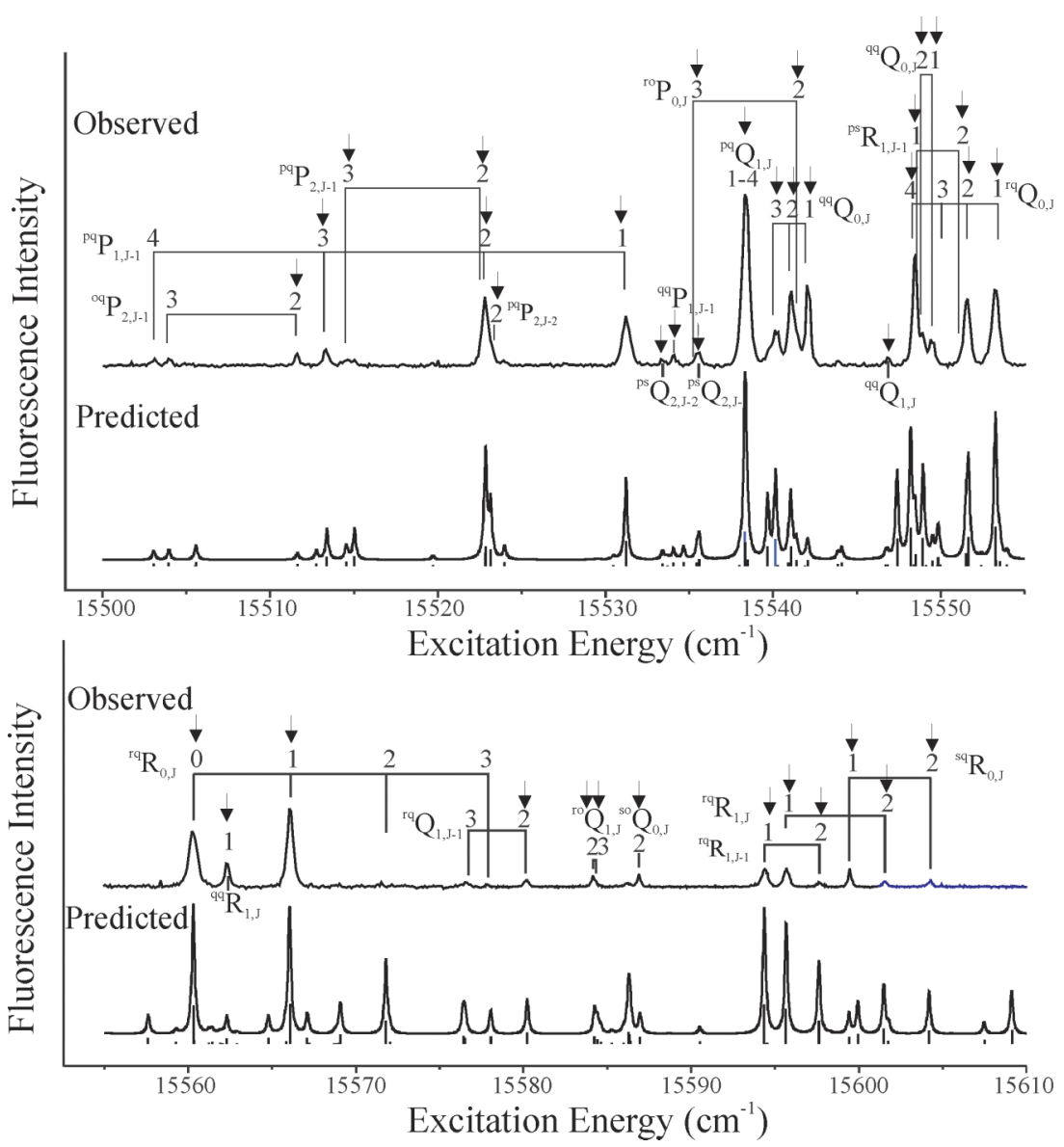

FIG. 2. The observed and predicted spectra laser excitation spectrum for the $0_{0}^{0} \tilde{X}^{1} \mathrm{~A}^{\prime} \rightarrow \tilde{A}^{1} \mathrm{~A}^{\prime \prime}$ band of SiHD and the associated assignment. The predicted stick spectrum and predicted spectrum assuming a Lorentzian line shape with a FWHM of $0.3 \mathrm{~cm}^{-1}$ obtained using the optimized spectroscopic parameters (vide infra). The features marked with arrows were recorded at high-resolution and used in the analysis. resulting DF spectra were integrated over the appropriate wavelength region to give the relative fluorescence intensity at a given delay from the laser excitation. The lower limit of the lifetime measurements of this experimental approach is set by the approximate 20 ns pulse width of the dye laser. Typically $10^{4}$ pulses at a given time delay were co-added resulting in a large background $\left(\sim 2 \times 10^{6}\right)$ signal due to dark current.

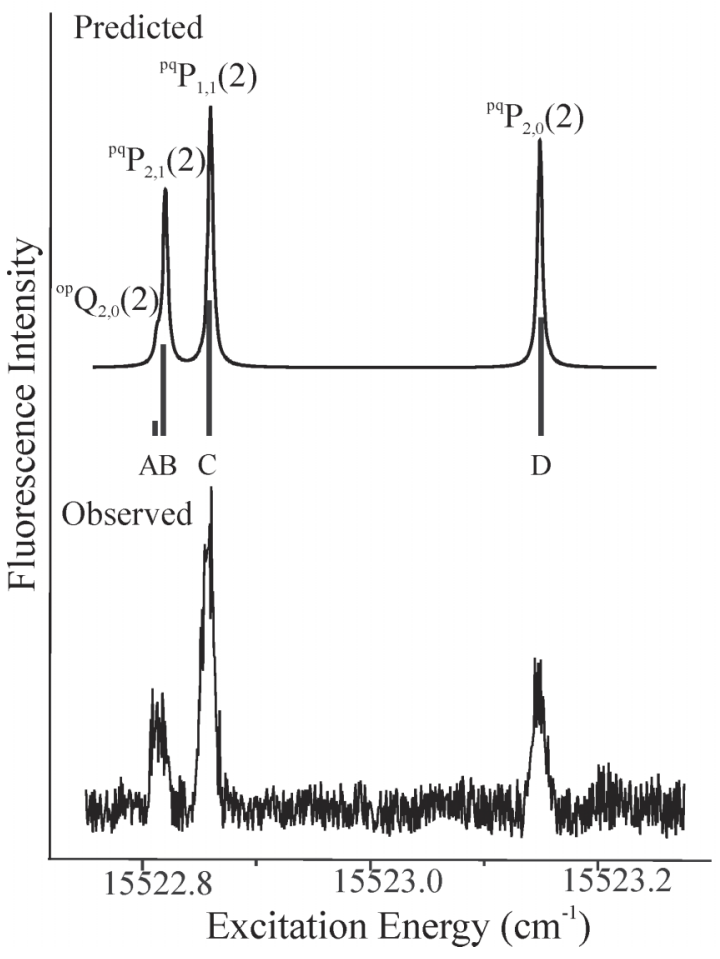

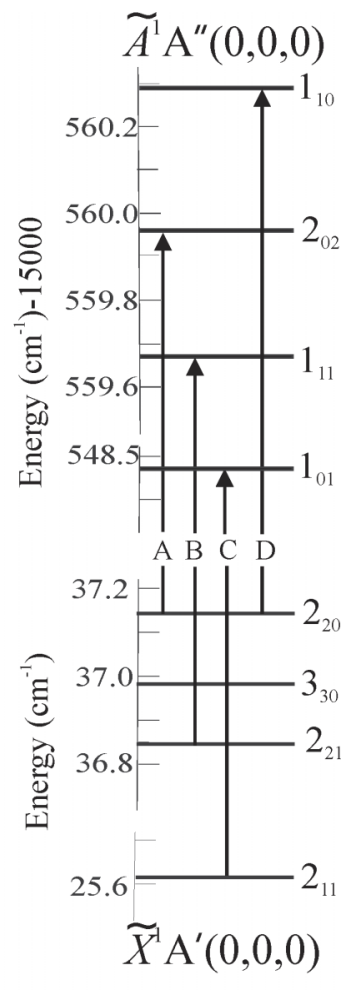

FIG. 3. Left: A $15 \mathrm{GHz}$ region of the observed and predicted high-resolution LIF excitation spectrum near $15523.0 \mathrm{~cm}^{-1}$. A 200 MHz FWHM Lorentzian line was used in the prediction. Right: The associated energy levels, quantum assignment, and branch feature assignments right side of Figure 3. The three intense features are $c$-type whereas the weak, unresolved feature is an axis-switching induced transition. 
TABLE I. Observed and calculated transition wavenumbers $\left(\mathrm{cm}^{-1}\right)$ for the $0_{0}^{0} \tilde{X}^{1} \mathrm{~A}^{\prime} \rightarrow \tilde{A}^{1} \mathrm{~A}^{\prime \prime}$ band of SiHD.

\begin{tabular}{|c|c|c|c|c|c|c|c|}
\hline \multirow{2}{*}{$\frac{\text { Assignment }}{{ }^{o{ }^{o} P_{21}(2)}}$} & \multirow[b]{2}{*}{$1_{01}-2_{21}$} & \multirow{2}{*}{$\frac{\mathrm{WN}\left(\mathrm{cm}^{-1}\right)^{\mathrm{a}}}{511.6179}$} & \multirow{2}{*}{$\begin{array}{c}\text { Obs.-Calc. } \\
-0.0035\end{array}$} & \multicolumn{2}{|c|}{ Assignment } & \multirow{2}{*}{$\frac{\mathrm{WN}\left(\mathrm{cm}^{-1}\right)^{\mathrm{a}}}{548.4776}$} & \multirow{2}{*}{$\begin{array}{r}\text { Obs.-Calc } \\
-0.0014\end{array}$} \\
\hline & & & & ${ }^{\mathrm{pq}} \mathrm{R}_{10}(1)$ & $2_{02}-1_{10}$ & & \\
\hline${ }^{\mathrm{pq}} \mathrm{P}_{12}(3)$ & $2_{02}-3_{12}$ & 513.3830 & 0.0013 & ${ }^{\mathrm{q}}{ }^{\mathrm{q}} \mathrm{Q}_{12}(2)$ & $22_{12}-2_{12}$ & 548.9514 & 0.0006 \\
\hline${ }^{\mathrm{pq}} \mathrm{P}_{22}(3)$ & $2{ }_{12}-3_{22}$ & 514.5400 & -0.0004 & ${ }^{\mathrm{q}} \mathrm{Q}_{11}(1)$ & $1_{11}-1_{11}$ & 549.5202 & -0.0018 \\
\hline${ }^{\mathrm{pq}} \mathrm{P}_{21}(2)$ & $1_{11}-2_{21}$ & 522.8187 & -0.0049 & ${ }^{\mathrm{ps}} \mathrm{R}_{11}(2)$ & $3_{03}-2_{11}$ & 551.5268 & 0.0023 \\
\hline${ }^{\mathrm{pq}} \mathrm{P}_{11}(2)$ & $1_{01}-2_{11}$ & 522.8616 & -0.0014 & ${ }^{\mathrm{rq}} \mathrm{Q}_{02}(2)$ & $2_{12}-2_{02}$ & 551.6623 & 0.0005 \\
\hline${ }^{\mathrm{pq}} \mathrm{P}_{20}(2)$ & $1_{10}-2_{20}$ & 523.1525 & 0.0064 & ${ }^{\mathrm{rq}} \mathrm{Q}_{01}(1)$ & $1_{11}-1_{01}$ & 553.2679 & -0.0049 \\
\hline${ }^{\mathrm{pq}} \mathrm{P}_{10}(1)$ & $0_{00}-1_{10}$ & 531.2283 & 0.0008 & ${ }^{\mathrm{rq}} \mathrm{R}_{00}(0)$ & $1_{10^{-}} 0_{00}$ & 560.2951 & 0.0058 \\
\hline${ }^{\mathrm{ps}} \mathrm{Q}_{20}(2)$ & $2_{12}-2_{20}$ & 533.4157 & 0.0029 & ${ }^{\mathrm{q}} \mathrm{R}_{11}(1)$ & $2{ }_{11}-1_{11}$ & 562.2898 & -0.0018 \\
\hline${ }^{\mathrm{qq}} \mathrm{P}_{11}(2)$ & $1_{11}-2_{11}$ & 534.0653 & 0.0000 & ${ }^{\mathrm{rq}} \mathrm{R}_{01}(1)$ & $22_{11}-1_{01}$ & 566.0411 & -0.0013 \\
\hline${ }^{\mathrm{ro}} \mathrm{P}_{03}(3)$ & $2_{11}-3_{03}$ & 535.4576 & -0.0001 & ${ }^{\mathrm{rq}} \mathrm{Q}_{11}(2)$ & $22_{21}-2_{11}$ & 580.2206 & 0.0024 \\
\hline${ }^{\mathrm{pq}} \mathrm{Q}_{21}(2)$ & $2_{11}-2_{21}$ & 535.593 & -0.0002 & ${ }^{\mathrm{ro}} \mathrm{Q}_{12}(2)$ & $2_{20}-2_{12}$ & 584.2425 & -0.0008 \\
\hline${ }^{\mathrm{pq}} \mathrm{Q}_{11}(1)$ & $1_{01}-1_{11}$ & 538.3212 & 0.0015 & ${ }^{\mathrm{ro}} \mathrm{Q}_{13}(3)$ & $3_{21}-3_{13}$ & 584.6116 & 0.0001 \\
\hline${ }^{\mathrm{pq}} \mathrm{Q}_{12}(2)$ & $2_{02}-2_{12}$ & 538.3557 & 0.0010 & ${ }^{\mathrm{so}} \mathrm{Q}_{02}(2)$ & $2_{20}-2_{02}$ & 586.9522 & -0.0022 \\
\hline${ }^{\mathrm{pq}} \mathrm{Q}_{13}(3)$ & $3_{03}-3_{13}$ & 538.5077 & 0.0008 & ${ }^{\mathrm{rq}} \mathrm{R}_{10}(1)$ & $220^{-} 1_{10}$ & 594.3686 & 0.0010 \\
\hline${ }^{\mathrm{q}} \mathrm{Q}_{03}(3)$ & $3_{03}-3_{03}$ & 540.1481 & 0.0007 & ${ }^{\mathrm{rq}} \mathrm{R}_{11}(1)$ & $22_{21}-1_{11}$ & 595.676 & 0.0011 \\
\hline${ }^{\mathrm{qq}} \mathrm{Q}_{02}(2)$ & $2_{02}-2_{02}$ & 541.0649 & -0.0009 & ${ }^{\mathrm{rq}} \mathrm{R}_{11}(2)$ & $3_{21}-2_{11}$ & 597.6255 & -0.0037 \\
\hline${ }^{\mathrm{ro}} \mathrm{P}_{02}(2)$ & $1_{10-2_{02}}$ & 541.3986 & 0.0032 & ${ }^{\mathrm{sq}} \mathrm{R}_{01}(1)$ & $22_{21}-1_{01}$ & 599.4254 & -0.0004 \\
\hline${ }^{\mathrm{q}}{ }^{\mathrm{q}} \mathrm{Q}_{01}(1)$ & $1_{01}-1_{01}$ & 542.0695 & -0.0011 & ${ }^{\mathrm{rq}} \mathrm{R}_{12}(2)$ & $3_{22}-2_{12}$ & 601.4955 & 0.0007 \\
\hline${ }^{\mathrm{qq}} \mathrm{Q}_{11}(2)$ & $2_{11}-2_{11}$ & 546.8315 & -0.0033 & ${ }^{\mathrm{sq}} \mathrm{R}_{02}(2)$ & $3_{22}-2_{02}$ & 604.2077 & 0.0019 \\
\hline${ }^{\mathrm{q}}{ }^{\mathrm{q}} \mathrm{Q}_{13}(3)^{\mathrm{b}}$ & $3_{13}-3_{13}$ & 548.2339 & $(0.0199)$ & & Std. dev. & $\mathrm{it}=0.0028 \mathrm{~cm}$ & \\
\hline${ }^{\mathrm{rq}} \mathrm{Q}_{04}(4)$ & $4_{14}-4_{04}$ & 548.2530 & -0.0010 & & & & \\
\hline
\end{tabular}

${ }^{\mathrm{a}}$ Transition wavenumber $\left(\mathrm{cm}^{-1}\right)-15000$.

${ }^{\mathrm{b}}$ Not included in fit.

\section{OBSERVATIONS}

The pulsed dye laser 2D spectrum in the $15500 \mathrm{~cm}^{-1}$ to $15600 \mathrm{~cm}^{-1}$ spectral region, which coincides with excitation of the $0_{0}^{0} \tilde{X}^{1} \mathrm{~A}^{\prime} \rightarrow \tilde{A}^{1} \mathrm{~A}^{\prime \prime}$ band of SiHD and the $0_{0}^{0} \tilde{X}^{1} \mathrm{~A}_{1} \rightarrow \tilde{A}^{1} \mathrm{~B}_{1}$ bands of $\mathrm{SiH}_{2}$ and $\mathrm{SiD}_{2}$, is presented in the center panel of Figure 1. The laser excitation wavelength is indicated on the horizontal axis and the DF wavelength on the vertical axis. Tracking the monochromator causes the vertical axis (LIF Emission Wavelength) to vary nearly linearly as function of excitation wavelength; at the beginning of the scan
(15 $500 \mathrm{~cm}^{-1}$ ), the center of the $75 \mathrm{~nm}$ spectral window is $677.5 \mathrm{~nm}$ whereas at the end of the scan $\left(15600 \mathrm{~cm}^{-1}\right)$, it is $681.7 \mathrm{~nm}$. The widely spaced features in the middle of the $2 \mathrm{D}$ spectra correspond to the $\tilde{A}^{1} \mathrm{~A}^{\prime \prime}(000) \rightarrow \tilde{X}^{1} \mathrm{~A}^{\prime}(010)$ and $\tilde{A}^{1} \mathrm{~B}_{1}(000) \rightarrow \tilde{X}^{1} \mathrm{~A}_{1}(010)$ emissions resulting from exciting the $0_{0}^{0} \tilde{X}^{1} \mathrm{~A}^{\prime} \rightarrow \tilde{A}^{1} \mathrm{~A}^{\prime \prime}$ band of SiHD and the $0_{0}^{0} \tilde{X}^{1} \mathrm{~A}_{1} \rightarrow \tilde{A}^{1} \mathrm{~B}_{1}$ bands of $\mathrm{SiH}_{2}$ and $\mathrm{SiD}_{2}$, respectively. The DF near 710 $\mathrm{nm}$ is the $\tilde{A}^{1} \mathrm{~B}_{1}(000) \rightarrow \tilde{X}^{1} \mathrm{~A}_{1}(020)$ emission associated with the excitation of the $\mathrm{SiH}_{2} 0_{0}^{0} \tilde{X}^{1} \mathrm{~A}_{1} \rightarrow \tilde{A}^{1} \mathrm{~B}_{1}$ band. The two compact, red-degraded bands in the DF spectra near $668 \mathrm{~nm}$ and $692 \mathrm{~nm}$ are tentatively identified ${ }^{64}$ as the $(7,1) F \rightarrow X$

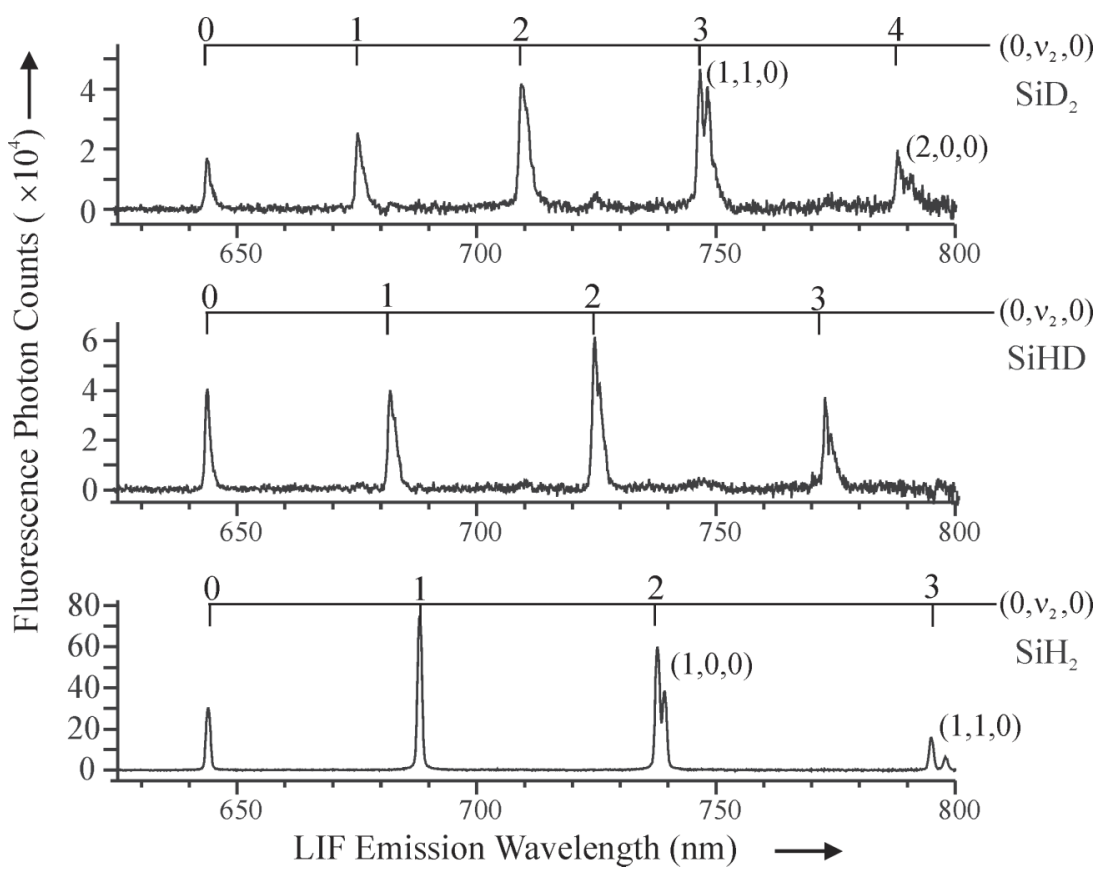

FIG. 4. The dispersed fluorescence spectra for $\mathrm{SiH}_{2}$ (bottom), SiHD (middle), and $\mathrm{SiD}_{2}$ (top) resulting from pulsed dye laser excitation of the ${ }^{\mathrm{P}} \mathrm{P}_{1}(1) \quad\left(v=15532.5 \mathrm{~cm}^{-1}\right),{ }^{\mathrm{pq}} \mathrm{Q}_{11}(1)$ $\left(v=15538.3 \mathrm{~cm}^{-1}\right)$, and ${ }^{\mathrm{P}} \mathrm{R}_{1}(1) \quad(v$ $\left.=15542.3 \mathrm{~cm}^{-1}\right)$ transitions, respectively. 
and $(7,2) F \rightarrow X$ emissions resulting from the laser excitation of the $(7,0) F \leftarrow X$ band of $\mathrm{Si}_{2}$ near $15572 \mathrm{~cm}^{-1}$.

At the right side of Figure 1 are the off-resonance detected laser excitation spectra obtained from the vertical integration of the intensities of the three horizontal slices marked by the dashed red rectangles. $\mathrm{The}^{\mathrm{SiH}_{2}}$ (top) and $\mathrm{SiD}_{2}$ (bottom) spectra are very similar to previously reported LIF spectra of a jet-cooled sample. ${ }^{18,19}$ In those earlier studies, the spectral congestion was avoided by using either phenylsilane $\left(\varphi-\mathrm{SiH}_{3}\right)$ or phenylsilane- $\alpha-d_{3}\left(\varphi-\mathrm{SiD}_{3}\right)$ as a precursor in a photolysis scheme for generating either a nearly pure $\mathrm{SiH}_{2}$ or $\mathrm{SiD}_{2}$ sample. Here DF wavelength selectivity of the 2D spectroscopic technique is exploited to extract the spectra of the individual isotopologues from the mixed isotopologue sample. The on-resonance excitation spectrum (not shown) obtained by vertical integration of the band near $642 \mathrm{~nm}$ in the 2D spectrum results in an unassignable, highly overlapped spectrum of $\mathrm{SiH}_{2}, \mathrm{SiD}_{2}, \mathrm{SiHD}$, and $\mathrm{Si}_{2}$. The $1 \mu \mathrm{s}$ CCD detector gate width biases against the detection of levels that pre-dissociate on a short time scale. Hence, the excitation spectrum for $\mathrm{SiH}_{2}$ (top) is very sparse compared to that of $\mathrm{SiD}_{2}$ (bottom) where the predissociation is less extensive. Although the excitation spectrum of $\mathrm{SiD}_{2}$ exhibits a recognizable pattern of branches, no such pattern is obvious in the corresponding spectrum of SiHD. On the left side of Figure 1 is the DF spectrum resulting from laser excitation of ${ }^{\mathrm{P}} \mathrm{P}_{1}(1) 0_{0}^{0} \tilde{X}^{1} \mathrm{~A}_{1} \rightarrow \tilde{A}^{1} \mathrm{~B}_{1}$ transition of $\mathrm{SiH}_{2}$ at $15532 \mathrm{~cm}^{-1}$. The spectrum was obtained from the horizontal integration of the intensities of the vertical slice marked by the dashed blue rectangle. The $\tilde{A}^{1} \mathrm{~B}_{1}(0,0,0) \rightarrow \tilde{X}^{1} \mathrm{~A}_{1}(0,1,0)$ emission feature occurs at $687.6 \mathrm{~nm}$.

A more detailed pulsed dye laser excitation spectrum for SiHD is presented in Figure 2. Also presented are the predicted stick spectrum and predicted spectrum assuming a Lorentzian line shape with a FWHM of $0.1 \mathrm{~cm}^{-1}$ obtained using the optimized spectroscopic parameters (vide infra). A rotational temperature of $20 \mathrm{~K}$ was used based upon a comparison of the observed and predicted intensities (vide infra) of the lines involving the lowest rotational levels, which do not predissociate. The FWHM of the predicted spectra is approximately half the observed width in order to emphasize overlapped character. A $\Delta^{K a} \Delta^{K c} \Delta J_{K a K c}\left(J^{\prime \prime}\right)$ designation is being used for branch feature assignment (vide infra). Highresolution 2D spectra of the features marked with arrows in Figure 2 were recorded by replacing the pulsed dye laser with a single frequency, cw-dye laser. The $15 \mathrm{GHz}$ region of the observed and predicted high-resolution spectrum near $15523.0 \mathrm{~cm}^{-1}$ is presented on the left in Figure 3. A 200 MHz FWHM Lorentzian line was used in the simulation. The associated energy levels, quantum assignment, and branch feature assignments are given on the right side of Figure 3. The three intense features are $c$-type transitions, whereas the weak, unresolved feature is an axis-switching induced transition. The 40 measured transition frequencies and assigned quantum number assignments are given in Table I. Also given are the differences between the observed and calculated transition wavenumbers and the standard deviation of the fit.

The dispersed fluorescence spectra for $\mathrm{SiH}_{2}, \mathrm{SiHD}$, and $\mathrm{SiD}_{2}$ resulting from pulsed dye laser excitation of the
${ }^{\mathrm{p}} \mathrm{P}_{1}(1)\left(\tilde{v}=15532.5 \mathrm{~cm}^{-1}\right),{ }^{18}{ }^{\mathrm{pq}} \mathrm{Q}_{11}(1)\left(\tilde{v}=15538.3 \mathrm{~cm}^{-1}\right)$, and $\left.\mathrm{P}_{1}(1)\right)\left(\tilde{v}=15542.3 \mathrm{~cm}^{-1}\right)^{19}$ transitions, respectively, are presented in Figure 4. The DF spectra are primarily progressions in the $\left(0, v_{2}{ }^{\prime \prime}, 0\right)$ mode. Due to the near resonance of multiples of $v_{1}, v_{2}$, and $v_{3}$ vibrational frequencies for the $\tilde{X}^{1} \mathrm{~A}_{1}$ state of $\mathrm{SiH}_{2}$, and to a lesser extent for the $\tilde{X}^{1} \mathrm{~A}_{1}$ state of $\mathrm{SiD}_{2}$, the DF spectra of these two molecules exhibit additional features from the $1 v_{1}-2 v_{2}$ Fermi resonances as well as $2 v_{1}-2 v_{3}$ Darling-Denison resonance. ${ }^{18-20,65}$ The weaker feature on the red side of the SiHD emissions are most likely due to the $1_{01} \rightarrow 2_{11}$ transition or caused by simultaneously pumping multiple transitions. Note that the DF spectral features for $\mathrm{SiH}_{2}$ are sharp whereas those for $\mathrm{SiHD}$, and more so for $\mathrm{SiD}_{2}$ are broader and red-degraded. This is a consequence of the predissociation which is more prevalent in $\mathrm{SiH}_{2}$ and the fact that the long detection gate of the CCD $(1 \mu \mathrm{s})$ biases towards the detection of long-lived levels. The $\tilde{X}^{1} \mathrm{~A}^{\prime}$ vibronic energies, $\mathrm{E}\left(v_{1}, v_{2}, v_{3}\right)$, extracted from the observed spacing of the DF
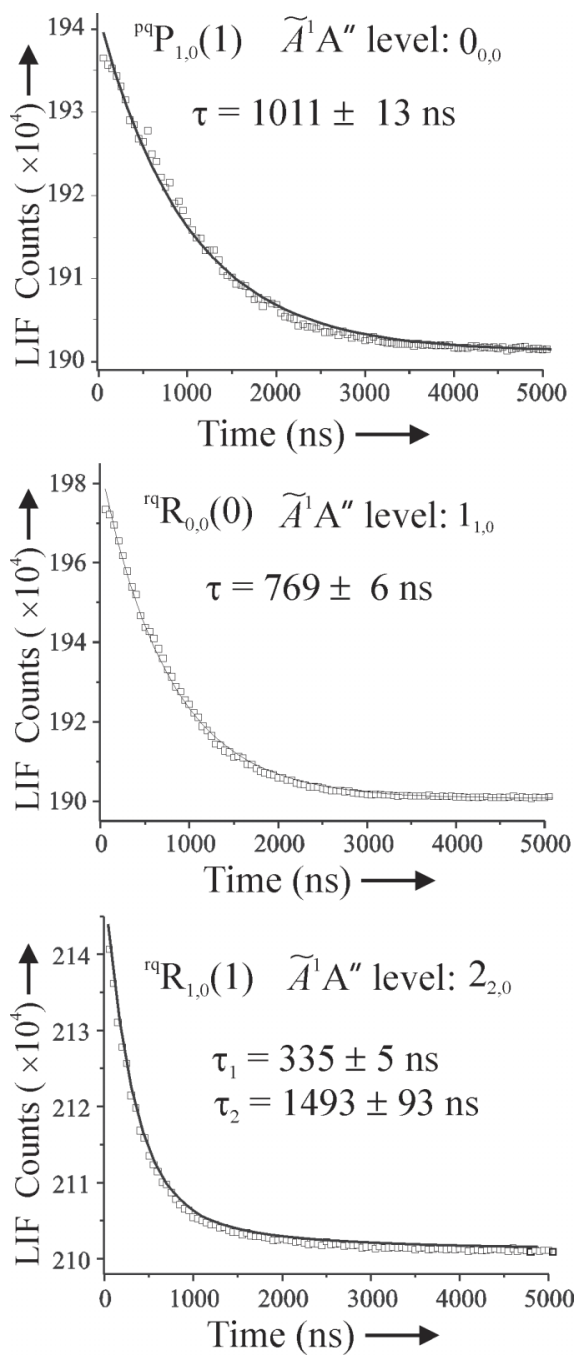

FIG. 5. The decay fluorescence curves resulting from excitation of the ${ }^{p q} P_{10}(1)\left(v=15531.2283 \mathrm{~cm}^{-1}\right)($ top $),{ }^{r q} R_{00}(0)\left(v=15560.2951 \mathrm{~cm}^{-1}\right)$ (middle), and ${ }^{\mathrm{rq}} \mathrm{R}_{10}(1)\left(v=15566.0411 \mathrm{~cm}^{-1}\right)$ (bottom) transitions. The fluorescence from the ${ }^{\mathrm{rq}} \mathrm{R}_{10}(1)$ line exhibits bi-exponential behavior. The amplitudes of for the bi-exponential curve are 40016 counts $\left(\tau_{1}\right)$ and 5686 counts $\left(\tau_{2}\right)$. The associated $\tilde{A}^{1} \mathrm{~A}^{\prime \prime}(0,0,0)$ energy level and resulting lifetimes are indicated in Figure 8. 
TABLE II. Fluorescence lifetimes (ns) and relative energies for the $A^{1} \mathrm{~A}^{\prime \prime}(0,0,0)$ state.

\begin{tabular}{lccc}
\hline \hline Line & Transition & Lifetime $(\mathrm{ns})$ & Energy $\left(\mathrm{cm}^{-1}\right)^{\mathrm{a}}$ \\
\hline${ }^{\mathrm{pq}} \mathrm{P}_{10}(1)$ & $0_{00}-1_{10}$ & $1011 \pm 13$ & 0 \\
${ }^{\mathrm{pq}} \mathrm{R}_{10}(1)$ & $2_{02}-1_{10}$ & $814 \pm 4$ & 17.25 \\
${ }^{\mathrm{rq}} \mathrm{R}_{00}(0)$ & $1_{10}-0_{00}$ & $769 \pm 6$ & 17.58 \\
${ }^{\mathrm{rq}} \mathrm{Q}_{02}(2)$ & $2_{12}-2_{02}$ & $739 \pm 5$ & 27.85 \\
${ }^{\mathrm{rq}} \mathrm{R}_{01}(1)$ & $2_{11}-1_{01}$ & $835 \pm 5$ & 29.73 \\
${ }^{\mathrm{rq}} \mathrm{R}_{10}(1){ }^{\mathrm{b}}$ & $2_{20}-1_{10}$ & $335 \pm 5$ & 63.14 \\
& $2_{20}-1_{10}$ & $1493 \pm 93$ & 63.14 \\
\hline \hline
\end{tabular}

a Relative to the $0_{00}$ level of the $\tilde{A}^{1} \mathrm{~A}^{\prime \prime}(0,0,0)$ state.

${ }^{\mathrm{b}} \mathrm{Bi}$-exponential behavior.

spectrum are $\mathrm{E}(0,1,0)=868.3 \mathrm{~cm}^{-1}, \mathrm{E}(0,2,0)=1734.2 \mathrm{~cm}^{-1}$, and $(0,3,0)=2589.1 \mathrm{~cm}^{-1}$.

The fluorescence decay curves resulting from excitation of the ${ }^{\mathrm{pq}} \mathrm{P}_{10}(1) \quad\left(\tilde{v}=15 \quad 531.2283 \quad \mathrm{~cm}^{-1}\right),{ }^{\mathrm{r}} \mathrm{R}_{00}(0) \quad(\tilde{v}$ $\left.=15560.2951 \mathrm{~cm}^{-1}\right)$, and ${ }^{\mathrm{rq}} \mathrm{R}_{10}(1)\left(\tilde{v}=15566.0411 \mathrm{~cm}^{-1}\right)$ lines are presented in Figure 5. The decay curves associated with the ${ }^{\mathrm{pq}} \mathrm{R}_{10}(1),{ }^{\mathrm{rq}} \mathrm{Q}_{02}(2)$, and ${ }^{\mathrm{rq}} \mathrm{R}_{01}(1)$ lines were also recorded. The decay curves for all lines except the ${ }^{\mathrm{rq}} \mathrm{R}_{10}(1)$ were satisfactorily fit to a single exponential function. The ${ }^{\mathrm{rq}} \mathrm{R}_{10}(1)$, which has the shortest radiative lifetime, exhibited a bi-exponential behavior. The resulting lifetimes and associated errors are presented in Table II.

\section{ANALYSIS}

\section{A. Energies and transition frequencies}

The SiHD DF spectrum, which exhibited a $\tilde{A}^{1} \mathrm{~A}^{\prime \prime}(0,0,0) \rightarrow$ $\tilde{X}^{1} \mathrm{~A}^{\prime}\left(0, v_{2}, 0\right)$ progression, was fit to the simple anharmonic expression

$$
G\left(0, v_{2} 0\right)=\omega_{2}\left(v_{2}+1 / 2\right)+\mathrm{x}_{22}\left(v_{2}+1 / 2\right)^{2}
$$

to give $\omega_{2}=872.9(11) \mathrm{cm}^{-1}$ and $\mathrm{x}_{22}=-3.2(4) \mathrm{cm}^{-1}$ and a standard deviation of the fit $=2.0 \mathrm{~cm}^{-1}$. The value derived from the analysis of the infrared absorption measurement of a matrix isolation sample $\mathrm{e}^{52}$ is $854.3 \mathrm{~cm}^{-1}$.
Initial assignment of the $c$-type transitions in the excitation spectrum was readily accomplished by predicting the spectrum using estimated rotational parameters based upon the previously determined structure ${ }^{25}$ of $\mathrm{SiH}_{2}$. Combination/differences revealed that the energies were not severely perturbed. Once the assignment of the additional axisswitching transitions was obtained (vide infra), a direct fit to the precisely measured transition wavenumbers of Table I was performed using a non-linear least squares fitting procedure. The energies for both the $\tilde{X}^{1} \mathrm{~A}^{\prime}$ and $\tilde{A}^{1} \mathrm{~A}^{\prime \prime}$ states were modelled using the standard Watson $A$-type Hamiltonian,

$$
\begin{aligned}
\hat{\mathrm{H}}^{\mathrm{rot}=} & \frac{1}{2}(B+C) \hat{\mathrm{J}}^{2}+\left[A-\frac{1}{2}(B+C)\right] J_{\mathrm{a}}^{2}+\frac{1}{4}(B-C)\left(J_{+}^{2}+J_{-}^{2}\right) \\
& -\Delta_{J} \hat{\mathrm{J}}^{4}-\Delta_{J K} J_{\mathrm{a}}^{2} \hat{\mathrm{J}}^{2}-\Delta_{\mathrm{K}} J_{\mathrm{a}}^{4}-\delta_{\mathrm{J}} \hat{\mathrm{J}}^{2}\left(J_{+}^{2}+J_{-}^{2}\right) \\
& -\frac{1}{2} \delta_{K}\left[J_{\mathrm{a}}^{2},\left(J_{+}^{2}+J_{-}^{2}\right)\right]_{+},
\end{aligned}
$$

where []$_{+}$is the anti-commutator. The eigenvalues and eigenvectors were obtained by diagonalization of a prolate symmetric top basis set representation of $\hat{\mathrm{H}}^{\text {rot }}$. In the end, 39 of the 40 precisely measured lines were used as input to a non-linear least squares fitting procedure. In addition to the optimized rotational parameters $\left(A_{0}, B_{0}\right.$, and $\left.C_{0}\right)$ and the origin $\left(T_{00}\right)$, fits including various combinations of the centrifugal distortion parameters were attempted. Only $\Delta_{J K}$ for the $\tilde{X}^{1} \mathrm{~A}^{\prime}$ state and $\Delta_{K}$ and $\delta_{J}$ for the $\tilde{A}^{1} \mathrm{~A}^{\prime \prime}$ state were required. The difference between the observed and calculated transition wavenumbers given in Table I does not exhibit any systematic pattern. The standard deviation of the fit $\left(=0.0027 \mathrm{~cm}^{-1}\right)$ is commensurate with the estimated measurement uncertainty. The residual for the excluded ${ }^{\mathrm{q} q} \mathrm{Q}_{13}(3)\left(\tilde{v} 15548.2339 \mathrm{~cm}^{-1}\right)$ line was $0.0186 \mathrm{~cm}^{-1}$. No other transitions associated with the $3_{13}$ rotational level of the $\tilde{A}^{1} \mathrm{~A}^{\prime \prime}$ state were observed. The optimized parameters for SiHD as well as those for the previously determined values for the $\tilde{X}^{1} \mathrm{~A}_{1}$ and $\tilde{A}^{1} \mathrm{~B}_{1}$ states of $\mathrm{SiH}_{2}{ }^{25,26}$ and $\mathrm{SiD}_{2}{ }^{19}$ are given in Table III.

\section{B. Intensities and spectral simulation}

\begin{tabular}{|c|c|c|c|c|c|c|}
\hline & \multicolumn{2}{|c|}{$\mathrm{SiHD}^{\mathrm{a}}$} & \multicolumn{2}{|c|}{$\mathrm{SiH}_{2}$} & \multicolumn{2}{|c|}{$\mathrm{SiD}_{2}$} \\
\hline & $\tilde{X}^{1} \mathrm{~A}^{\prime}$ & $\tilde{A}^{1} \mathrm{~A}^{\prime \prime}$ & $\tilde{X}^{1} \mathrm{~A}_{1}{ }^{\mathrm{b}}$ & $\tilde{A}^{1} \mathrm{~B}_{1}{ }^{\mathrm{c}}$ & $\tilde{X}^{1} \mathrm{~A}_{1}{ }^{\mathrm{d}}$ & $\tilde{A}^{1} \mathrm{~B}_{1}{ }^{\mathrm{d}}$ \\
\hline$T_{00}$ & & $15542.709(2)$ & & 15 547.773(9) & & $15539.875(2)$ \\
\hline$A_{0}$ & 7.6178(17) & 14.4091(23) & $8.09898(10)$ & $18.324(2)$ & $4.334(1)$ & $9.6288(9)$ \\
\hline$B_{0}$ & $3.8651(5)$ & $3.1872(8)$ & $7.02363(8)$ & $4.8995(9)$ & $3.5186(5)$ & $2.4563(7)$ \\
\hline$C_{0}$ & $2.5320(4)$ & $2.5719(8)$ & $3.70257(3)$ & $3.7661(3)$ & $1.9194(3)$ & $1.9262(8)$ \\
\hline$\Delta_{J}\left(\times 10^{-3}\right)$ & & & $0.461(1)$ & $0.089(5)$ & $0.10(1)$ & $0.006(7)$ \\
\hline$\Delta_{J K}\left(\times 10^{-3}\right)$ & $0.9(2)$ & $17.8(5)$ & $-1.422(5)$ & -0.337 & $-0.38(4)$ & $-0.18(8)$ \\
\hline$\Delta_{K}\left(\times 10^{-3}\right)$ & & & 2.34(1) & $35.2(1)$ & $0.8(1)$ & 8.1(3) \\
\hline$\delta_{J}\left(\times 10^{-3}\right)$ & & $-0.52(3)$ & $0.2052(6)$ & $0.041(3)$ & $0.046(5)$ & $0.015(3)$ \\
\hline$\delta_{K}\left(\times 10^{-3}\right)$ & & & & & -0.037 & $-0.3(3)$ \\
\hline
\end{tabular}

Modeling the spectrum was critical for assignment and analysis. These calculations were performed by generating

TABLE III. Spectroscopic parameters $\left(\mathrm{cm}^{-1}\right)$ for the $\tilde{X}^{1} \mathrm{~A}^{\prime}(0,0,0)$ and $\tilde{A}^{1} \mathrm{~A}^{\prime \prime}(0,0,0)$ states of SiHD.

${ }^{\mathrm{a}}$ This work. The numbers in parenthesis represents a $1 \sigma$ error estimate.

${ }^{\mathrm{b}}$ Reference 26 .

${ }^{\mathrm{c}}$ Reference 25 .

${ }^{\mathrm{d}}$ Reference 19 . 
the electric dipole transition moment matrix, $\underline{\mu}$, and then

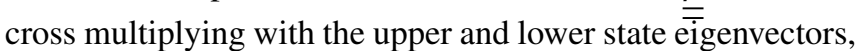
$\underline{\mathrm{a}}\left(\tilde{A}^{1} \mathrm{~A}^{\prime \prime}, \tilde{X}^{1} \mathrm{~A}^{\prime}\right)$, to obtain the appropriate transition moment, TM,

$$
\operatorname{TM}(\tilde{A} \leftrightarrow \tilde{X})=\underline{\mathrm{a}}\left(\tilde{A}^{1} \mathrm{~A}^{\prime \prime}\right) \cdot \underline{\underline{\mu}} \cdot \underline{\mathrm{a}}\left(\tilde{X}^{1} \mathrm{~A}^{\prime}\right)
$$

The TM was then squared and multiplied by the Boltzmann factors appropriate for the approximate $20 \mathrm{~K}$ internal temperature. A Lorentzian line shape was superimposed to give the predicted spectra as in Figures 1-3.

Initial simulations used the principal axis systems of the $\tilde{X}^{1} \mathrm{~A}^{\prime}$ and $\tilde{A}^{1} \mathrm{~A}^{\prime \prime}$ states to calculate the eigenvectors, a(principal) $\left(\tilde{A}^{1} A^{\prime \prime}, \tilde{X}^{1} A^{\prime}\right)$ and transition moment matrix, $\mu$, to predict the relative intensities of the $c$-type transitions. The method was checked by comparing observed and predicted relative intensities for the spectral features of the $\tilde{X}^{1} \mathrm{~A}_{1} \rightarrow \tilde{A}^{1} \mathrm{~B}_{1}$ electronic transition of $\mathrm{SiH}_{2}$ and $\mathrm{SiD}_{2}$. It became clear that there were many additional, non $c$-type, spectral features in the $0_{0}^{0} \tilde{X}^{1} \mathrm{~A}^{\prime} \rightarrow \tilde{A}^{1} \mathrm{~A}^{\prime \prime}$ band of SiHD. Due to the $C_{2 v}$-symmetry of $\mathrm{SiH}_{2}$ and $\mathrm{SiD}_{2}$, the orientation of the principal axes is unaltered upon excitation, whereas for the lower symmetry SiHD molecules, the orientation of inertial axes of the ground and excited states do not coincide. The molecule-fixed axis system is defined by the Eckart conditions, which approximately separates the rotational motion from the vibrational motion. The Eckart conditions depend upon the instantaneous geometry for the electronic state in question. ${ }^{66}$ In order to describe an electronic transition of the molecule, two equilibrium configurations, and so two sets of moving axes must be considered. Hougen and Watson ${ }^{53}$ showed that when a molecule undergoes an electronic transition accompanied by a geometry change, it is necessary to consider moleculefixed axis systems of both electronic states. These axes have coincident center of mass origins, but one set is usually rotated with respect to the other. The two molecular fixed axis systems are related by a $3 \times 3$ rotation matrix $\mathbf{T}$ ("axis switching matrix"). ${ }^{53,55,67}$ The equilibria locations of the nuclei (vide infra) in the principal axes for the $A^{1} \mathrm{~A}^{\prime \prime}$ and $\tilde{X}^{1} \mathrm{~A}^{\prime}$ states are shown in Figure 6. A rotation angle, $\Omega_{0}$, that produces the rotation matrix, $\mathbf{T}$, which fulfills the Eckart condition is $21.7^{\circ}$ (Appendix). The location of the $\tilde{A}^{1} \mathrm{~A}^{\prime \prime}$ state nuclei in this rotated axis system (the Eckart axis system) is also shown in Figure 6, as are the angles that the principal and Eckart axes systems make relative to ones that bisect a line joining the $\mathrm{D}$ and $\mathrm{H}$ nuclei. The relative orientation of the $\mathrm{H}, \mathrm{D}$, and,

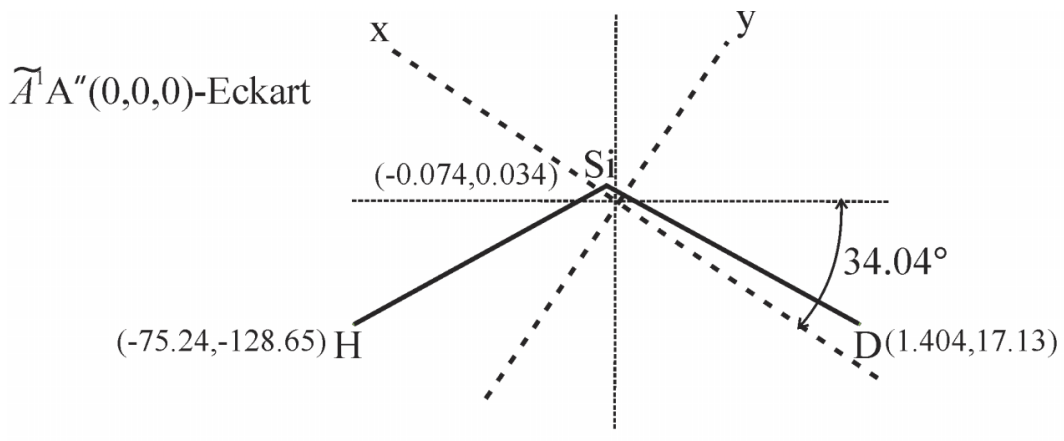

$\widetilde{A}^{\top} \mathrm{A}^{\prime \prime}(0,0,0)$-Principal

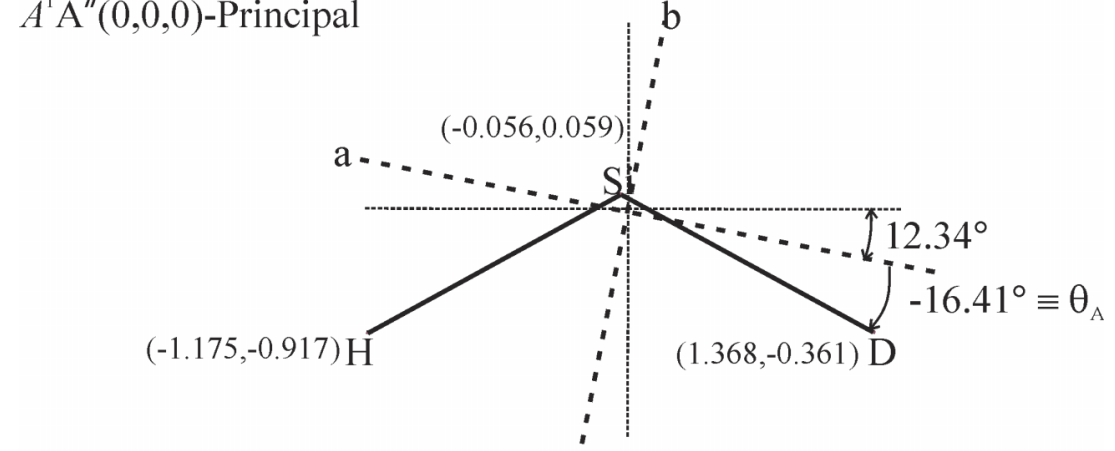

FIG. 6. The location of the nuclei in the principal axis system of the $\tilde{X}^{1} \mathrm{~A}^{\prime}$ state (bottom), the principal axis system of the $A^{1} \mathrm{~A}^{\prime \prime}$ (middle), and the Eckart axis system of the $A^{1} \mathrm{~A}^{\prime \prime}$ state (upper). Also shown are the angles that the principle axes system make relative to one that bisects a line joining the $\mathrm{D}$ and $\mathrm{H}$ nuclei.

$\widetilde{X}^{\mathrm{I}} \mathrm{A}^{\prime}(0,0,0)$-Principal

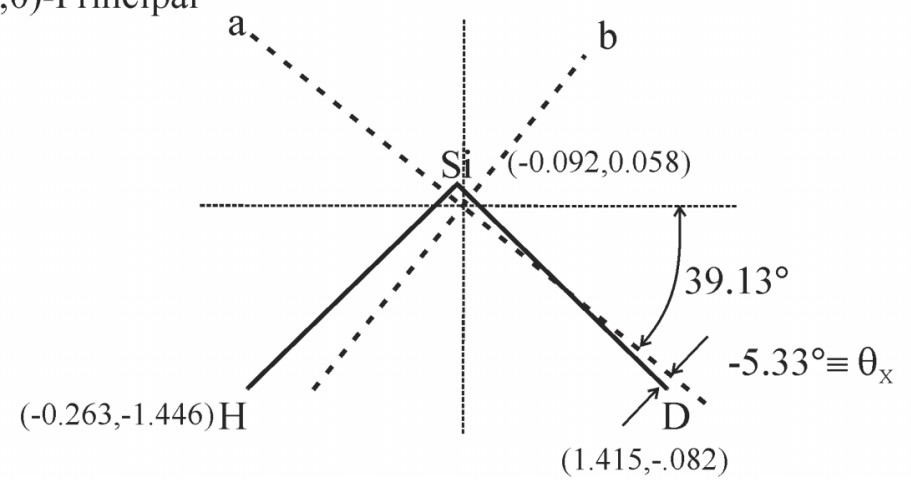




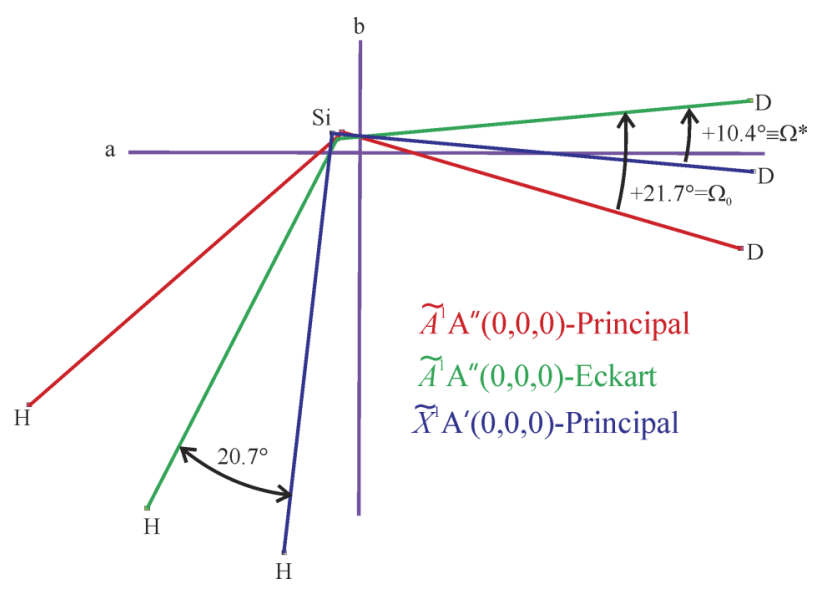

FIG. 7. The relative orientation of the $\mathrm{H}, \mathrm{D}$, and Si nuclei in the principal axis of the $\tilde{X}^{1} \mathrm{~A}^{\prime}$ and $A^{1} \mathrm{~A}^{\prime \prime}$ states, as well as that for the $A^{1} \mathrm{~A}^{\prime \prime}$ state in an Eckart axis. Note that the $21.7^{\circ}$ rotation of the principal axis of the $A^{1} \mathrm{~A}^{\prime \prime}$ state (see text) produces a geometry in the Eckart axis that approximately achieves a mass-weighted shift of the $\mathrm{H}$ and $\mathrm{D}$ nuclei relative to that of the $\tilde{X}^{1} \mathrm{~A}^{\prime}$ state.

Si nuclei in the principal axes of the $\tilde{X}^{1} \mathrm{~A}^{\prime}$ and $\tilde{A}^{1} \mathrm{~A}^{\prime \prime}$ states, as well as that for the $A^{1} \mathrm{~A}^{\prime \prime}$ state in the Eckart axis system, is given in Figure 7. Here the principal axes of the three are made to be coincident.

The inertial tensor in the Eckart axis system is nondiagonal and produces rotational parameters $A_{0}, B_{0}, C_{0}$, and $D_{0}$ of approximately $12.496 \mathrm{~cm}^{-1}, 4.683 \mathrm{~cm}^{-1}, 2.601 \mathrm{~cm}^{-1}$, and $3.698 \mathrm{~cm}^{-1}$, respectively (Appendix). These values were used to calculate the eigenvalues and eigenvectors for the $\tilde{A}^{1} \mathrm{~A}^{\prime \prime}$ state as described in Appendix. The Eckart axis system eigenvectors, a $\underline{\text { (Eckart })}\left(\tilde{A}^{1} \mathrm{~A}^{\prime \prime}\right)$, were then used in Eq. (3) to predict the transition moments and subsequently simulate the spectra.

\section{DISCUSSION}

A comparison of the observed and predicted spectra in Figure 2 reveals that numerous branch features were not observed even after accounting for the axis switching induced lines. Most obvious is the predicted ${ }^{\mathrm{rq}} \mathrm{R}_{02}(2)$ transition $\left(3_{12} \leftarrow\right.$ $2_{02}$ ) near $15571.66 \mathrm{~cm}^{-1}$. As other transitions originating from the 202 rotational level of the $\tilde{X}^{1} \mathrm{~A}^{\prime}$ state are observed, it was concluded that the $3_{12}$ rotational level of the $\tilde{A}^{1} \mathrm{~A}^{\prime \prime}$ state is pre-dissociative. It is also noteworthy that the $3_{13}$ level of $\tilde{A}^{1} \mathrm{~A}^{\prime \prime}$ state, which is approximately $4 \mathrm{~cm}^{-1}$ lower in energy than the $3_{12}$ level, is the upper energy terminus of the perturbed ${ }^{\mathrm{qq}} \mathrm{Q}_{13}(3)$ transition (Table I). The fluorescence lifetimes of the observed branch features provide additional insight into the predissociation process. The energy level pattern with the observed lifetimes and indicated perturbed and non-observed levels is given in Figure 8. The determined lifetime of $1011 \pm 13 \mathrm{~ns}$ for the $0_{00}$ level of the $\tilde{A}^{1} \mathrm{~A}^{\prime \prime}$ state is similar to the $1.1 \pm 0.17 \mu$ s and $0.93 \pm 0.38 \mu$ s values for the same rotational level of $\mathrm{SiH}_{2}$ and $\mathrm{SiD}_{2}$, respectively. ${ }^{18}$ A general trend of decreasing lifetime with increasing upper state energy is observed (Table II), similar to that observed for the other isotopologues. ${ }^{14,18,38}$ The correlation with $K_{a}$ values is more pronounced with the $0_{00}, 1_{10}$, and $2_{20}$

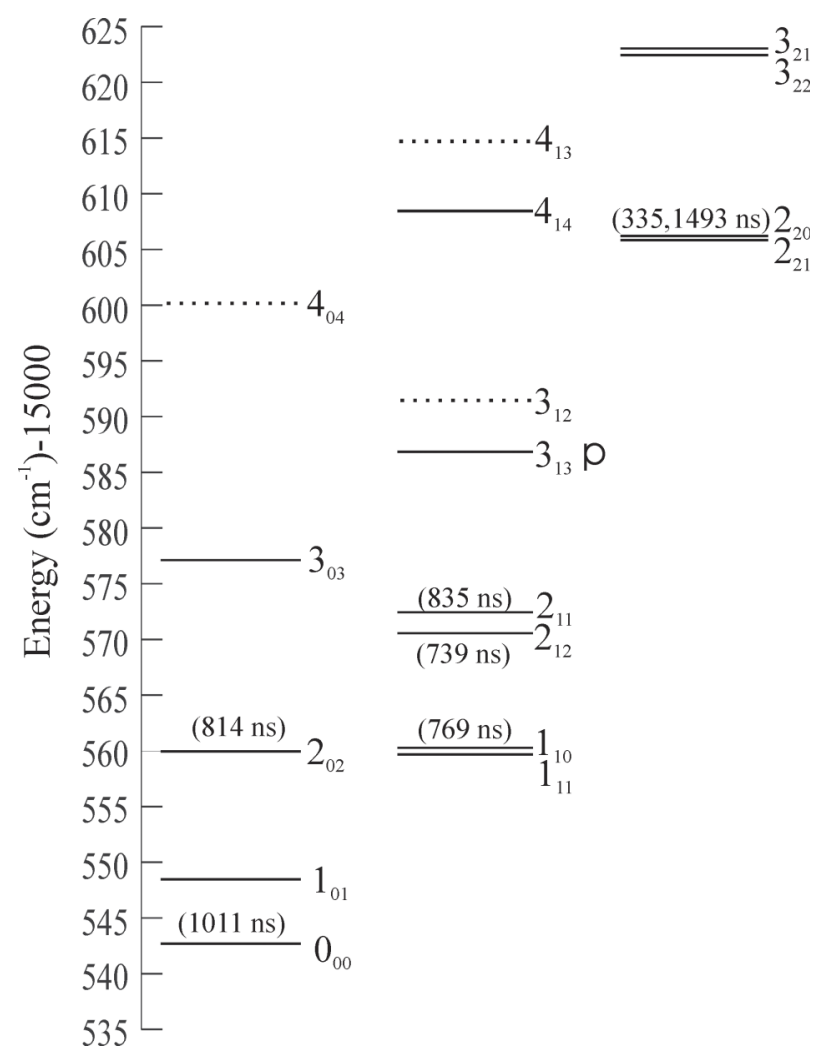

FIG. 8. The energy level pattern for the $A^{1} \mathrm{~A}^{\prime \prime}(0,0,0)$ state of SiHD. The fluorescence lifetimes are given in parentheses. The dashed lines indicate levels that were not detected due to low fluorescence quantum yield. The $3_{13}$ level is slightly perturbed.

lifetimes being $1011 \mathrm{~ns}, 769 \mathrm{~ns}$, and 335 ns, respectively. The $2_{11}$ level has a significantly longer lifetime than the $1_{10}$ level, which is $12 \mathrm{~cm}^{-1}$ lower in energy indicating that energy and/or $K_{\mathrm{a}}$ is not the only factor dictating predissociation rate. The bi-exponential decay curve for the $2_{20}$ level is dominated by the fast component (amplitude $=40016$ counts). The lifetime of the weaker (amplitude $=5686$ counts) slow component is comparable to that of the $0_{00}$ level. The most obvious explanation for the observed bi-exponential behavior is that two or more different transitions were simultaneously excited due to a blending of lines. ${ }^{14}$

The LIF excitation data set for SiHD (Table I) is less extensive than the data sets associated with the previous visible ${ }^{25}$ or infrared ${ }^{26}$ absorption spectra of $\mathrm{SiH}_{2}$ due mainly to the small fluorescence quantum yield for the higher rotational levels of the $\tilde{A}^{1} \mathrm{~A}^{\prime \prime}$ state. Accordingly, the spectroscopic parameters for SiHD are somewhat less well determined than those for $\mathrm{SiH}_{2}$. The precision of the determined $\mathrm{SiHD}$ parameters are comparable to those derived from the analysis the LIF spectrum of $\mathrm{SiD}_{2},{ }^{19}$ but the centrifugal distortion parameters for $\mathrm{SiD}_{2}$ are better determined because higher rotational levels were probed due to less pre-dissociation in $\mathrm{SiD}_{2}$ compared to $\mathrm{SiHD}$.

The inertial defect, $\Delta_{0}$, derived from $A_{0}, B_{0}$, and $C_{0}$ parameters of Table III are given in Table IV. The relative small values of $\Delta_{0}$ for the ground states of the three isotopologues are indicative of a rigid structure. The inertial defect is made up 
of three parts, resulting from vibration and electronic motion and centrifugal distortions. ${ }^{68,69}$ The centrifugal distortion part is usually negligible for low rotational levels. The vibrational part, $\Delta_{0}^{\mathrm{vib}}$, is a Coriolis effect; the electronic part, $\Delta_{0}^{\mathrm{el}}$, results from off diagonal matrix elements of the orbital angular momentum operator. The expression for $\Delta_{0}^{\mathrm{vib}}$ for molecules having $C_{2}$-symmetry (e.g., $\mathrm{SiH}_{2}$ and $\mathrm{SiD}_{2}$ ) is well documented. ${ }^{69}$ The expression for $C_{\mathrm{s}}$-symmetry molecule (e.g., SiHD) is readily obtained from the general expression ${ }^{68}$ and symmetry constraints ${ }^{70}$ to be

$$
\begin{aligned}
\Delta_{0}^{\mathrm{vib}}= & \frac{h}{\pi^{2} c}\left[\left(\mathrm{~V}_{1}+\frac{1}{2}\right)\left(\frac{\omega_{3}^{2}}{\omega_{1}\left(\omega_{3}^{2}-\omega_{1}^{2}\right)}\left(\zeta_{13}^{(c)}\right)^{2}+\frac{\omega_{2}^{2}}{\omega_{1}\left(\omega_{2}^{2}-\omega_{1}^{2}\right)}\left(\zeta_{12}^{(c)}\right)^{2}\right)\right. \\
& +\left(\mathrm{V}_{2}+\frac{1}{2}\right)\left(\frac{\omega_{3}^{2}}{\omega_{2}\left(\omega_{3}^{2}-\omega_{2}^{2}\right)}\left(\zeta_{23}^{(c)}\right)^{2}+\frac{\omega_{1}^{2}}{\omega_{3}\left(\omega_{1}^{2}-\omega_{2}^{2}\right)}\left(\zeta_{12}^{(c)}\right)^{2}\right) \\
& \left.+\left(\mathrm{V}_{3}+\frac{1}{2}\right)\left(\frac{\omega_{2}^{2}}{\omega_{3}\left(\omega_{2}^{2}-\omega_{3}^{2}\right)}\left(\zeta_{23}^{(c)}\right)^{2}+\frac{\omega_{1}^{2}}{\omega_{3}\left(\omega_{1}^{2}-\omega_{2}^{2}\right)}\left(\zeta_{13}^{(c)}\right)^{2}\right]\right) .
\end{aligned}
$$

In Eq. (4), $\zeta_{\mathrm{ij}}^{(\mathrm{c})}$ are the $c$-principal axis component of Coriolis coupling constants between the " $\mathrm{i}$-th" and " $\mathrm{j}$-th" vibrational mode and $\omega_{\mathrm{i}}$ is the harmonic frequency of the "i-th" mode. Theoretical predictions for $\zeta_{\mathrm{ij}}^{(\mathrm{c})}$ are only available for the ground states $\mathrm{SiH}_{2}, \mathrm{SiD}_{2}$, and $\mathrm{SiHD} .{ }^{37}$ As part of the present study, density functional theory ${ }^{71}$ (DFT) and time dependent density functional theory ${ }^{72}$ (TDDFT) employing the B3LYP hybrid functional ${ }^{73}$ and the $6-311 \mathrm{G}++(3 \mathrm{df}, 3 \mathrm{pd})$ basis set were used to predict $\zeta_{\mathrm{ij}}^{(\mathrm{c})}, \omega_{\mathrm{i}}$, and vibration-rotation parameters, $\alpha_{\mathrm{i}}$, needed for equilibrium structure determination(vide infra). The DFT-B3LYP and TDDFT-B3LYP calculations were implemented using the GAUSSIAN 03 quantum chemistry

TABLE IV. Inertial defect (amu- $\left.\AA^{2}\right)$.

\begin{tabular}{lcccc}
\hline \hline Molecule & $\Delta_{0}(\tilde{X})^{\mathrm{a}}$ & $\Delta_{0}^{\mathrm{vib}}(\tilde{X})^{\mathrm{b}}$ & $\Delta_{0}(\tilde{A})$ & $\Delta_{0}^{\mathrm{vib}}(\tilde{A})^{\mathrm{b}}$ \\
\hline $\mathrm{SiHD}$ & $0.0834(2)$ & 0.0884 & $0.0954(2)$ & 0.1035 \\
$\mathrm{SiH}_{2}$ & $0.07275(3)$ & 0.0771 & $0.11549(4)$ & 0.0897 \\
$\mathrm{SiD}_{2}$ & $0.10229(7)$ & 0.1071 & $0.13775(6)$ & 0.1243 \\
\hline
\end{tabular}

${ }^{\mathrm{a}}$ The numbers in parenthesis represents a $1 \sigma$ error estimate.

${ }^{b}$ Calculated using Eq. (4) and the DFT predicted Coriolis constants and vibrational frequencies (supplementary material). program package. ${ }^{74}$ It is not the objective to produce the best set of predicted values, but instead reasonably accurate values obtained at nearly the same level of theory for both the ground and excited states. The results are presented in supplementary material. ${ }^{75}$ The predicted $\zeta_{\mathrm{ij}}^{(\mathrm{c})}$ and $\omega_{\mathrm{i}}$ values were input into Eq. (4) to predict the $\Delta_{0}^{\text {vib }}$ values for the ground and excited states of $\mathrm{SiHD}, \mathrm{SiD}_{2}$ and $\mathrm{SiH}_{2}$, and are given in Table IV. The predicted $\Delta_{0}^{\mathrm{vib}}$ values for the ground states of the three isotopologues are in excellent agreement with the observed $\Delta_{0}$ values. In contrast, the predicted $\Delta_{0}^{\mathrm{vib}}$ values for the excited states are in relatively poor agreement with the observed $\Delta_{0}$ values. It is reasonable that the electronic contribution to $\Delta_{0}$ will be large for the excited states because of the proximity of the $\tilde{a}^{3} \mathrm{~B}_{1}, \tilde{A}^{1} \mathrm{~B}_{1}$, and $\tilde{B}^{1} \mathrm{~A}_{1}$ states in the case of $\mathrm{SiH}_{2}$ and $\mathrm{SiD}_{2}$ and the $\tilde{A}^{1} \mathrm{~A}^{\prime \prime}, \tilde{a}^{3} \mathrm{~A}^{\prime}$, and $\tilde{B}^{1} \mathrm{~A}^{\prime}$ states in the case of SiHD. Local perturbations in the excited state could also affect the interpretation of the rotational parameters.

The $A_{0}, B_{0}$, and $C_{0}$ rotational parameters of SiHD, $\mathrm{SiH}_{2}$, and $\mathrm{SiD}_{2}$ (Table III) were used to determine the equilibrium rotational constants, $A_{e}, B_{e}$, and $C_{e}$ for the ground

\begin{tabular}{|c|c|c|c|c|c|c|c|c|c|}
\hline \multicolumn{10}{|c|}{$\tilde{X}^{1} \mathrm{~A}^{\prime}$ or $\tilde{X}^{1} \mathrm{~A}_{1}$} \\
\hline & \multicolumn{3}{|c|}{$\mathrm{SiH}_{2}$} & \multicolumn{3}{|c|}{$\mathrm{SiHD}$} & \multicolumn{3}{|c|}{$\mathrm{SiD}_{2}$} \\
\hline$\alpha^{\mathrm{a}}$ & 0.00581 & 0.04036 & 0.14002 & -0.05797 & 0.02179 & 0.07721 & 0.00246 & 0.01437 & 0.05182 \\
\hline$v=0^{\mathrm{b}}$ & 8.09898 & 7.02363 & 3.70257 & 7.61767 & 3.86495 & 2.53193 & 4.33450 & 3.51856 & 1.91945 \\
\hline Equal. $^{\mathrm{c}}$ & 8.10188 & 7.04381 & 3.77258 & 7.58869 & 3.87585 & 2.57054 & 4.33573 & 3.52575 & 1.94536 \\
\hline \multicolumn{10}{|c|}{$\tilde{A}^{1} \mathrm{~A}^{\prime \prime}$ or $\tilde{A}^{1} \mathrm{~B}_{1}$} \\
\hline & \multicolumn{3}{|c|}{$\mathrm{SiH}_{2}$} & \multicolumn{3}{|c|}{$\mathrm{SiHD}$} & \multicolumn{3}{|c|}{$\mathrm{SiD}_{2}$} \\
\hline$\alpha^{\mathrm{a}}$ & -1.49540 & 0.05705 & 0.15187 & -1.01103 & 0.04175 & 0.08470 & -0.56198 & 0.02013 & 0.05659 \\
\hline$v=0^{\mathrm{b}}$ & 18.32410 & 4.89951 & 3.76611 & 14.40908 & 3.18713 & 2.57186 & 9.62878 & 2.45623 & 1.92621 \\
\hline Equal. $^{\mathrm{c}}$ & 17.57640 & 4.92804 & 3.84205 & 13.90357 & 3.20801 & 2.61421 & 9.34779 & 2.46630 & 1.95451 \\
\hline
\end{tabular}
and excited states of the three isotopologues. The required

TABLE V. Equilibrium rotational parameters.

\footnotetext{
${ }^{\mathrm{a}}$ The predicted rotation-vibration parameters (see text).

${ }^{\mathrm{b}}$ The experimentally determined $A_{0}, B_{0}$, and $C_{0}$ values from Table III.

${ }^{\mathrm{c}}$ The equilibrium rotational parameters $A_{\mathrm{e}}, B_{\mathrm{e}}$, and $C_{\mathrm{e}}$.
} 
TABLE VI. Geometrical structure.

\begin{tabular}{llllll}
\hline \hline & \multicolumn{2}{c}{$\tilde{X}^{1} \mathrm{~A}^{\prime}$ or $\tilde{X}^{1} \mathrm{~A}_{1}$} & & \multicolumn{2}{c}{$\tilde{A}^{1} \mathrm{~A}^{\prime \prime}$ or $\tilde{A}^{1} \mathrm{~B}_{1}$} \\
\cline { 2 - 3 } \cline { 5 - 6 } & $r_{\mathrm{e}}(\AA)^{\mathrm{a}}$ & $\theta_{\mathrm{e}}(\mathrm{deg})$ & & $r_{\mathrm{e}}(\AA)$ & $\theta_{\mathrm{e}}(\mathrm{deg})$ \\
\hline $\mathrm{SiHD}$ & $1.5145(8)$ & $91.2(6)$ & & $1.4846(11)$ & $122.49(22)$ \\
$\mathrm{SiH}_{2}$ & $1.5143(4)$ & $92.01(4)$ & & $1.4866(6)$ & $122.48(18)$ \\
$\mathrm{SiD}_{2}$ & $1.5134(3)$ & $92.07(2)$ & & $1.4855(6)$ & $122.48(10)$ \\
$\mathrm{All}\left(\mathrm{SiH}_{2}\right)^{\mathrm{b}}$ & $1.5137(3)$ & $92.04(5)$ & & $1.4853(5)$ & $122.48(8)$ \\
\hline \hline
\end{tabular}

${ }^{\mathrm{a}}$ The numbers in parenthesis represents a $1 \sigma$ error estimate.

${ }^{b}$ Obtained by simultaneously fitting the to the equilibrium rotational parameters of all three isotopologues.

rotation-vibration parameters, $\alpha_{\mathrm{i}}$, were obtained from the aforementioned electronic structure prediction. The resulting values are presented in Table V. The equilibrium geometrical parameters $\left(r_{\mathrm{e}}\right.$ and $\left.\theta_{\mathrm{e}}\right)$ for the ground and excited states of $\mathrm{SiHD}, \mathrm{SiH}_{2}$, and $\mathrm{SiD}_{2}$ were calculated from the determined $A_{e}$, $B_{e}$, and $C_{e}$ parameters using the STRFIT program. ${ }^{76}$ Fits for the individual isotopologues, as well as a global fit to all three isotopologues, are presented in Table VI. The determined $r_{\mathrm{e}}$ and $\theta_{\mathrm{e}}$ for the $\tilde{X}^{1} \mathrm{~A}_{1}$ states are 1.5137(3) $\AA$ and 92.04(5) ${ }^{\circ}$, which compares to the most recent wavefunction-based prediction ${ }^{45}$ of $1.5187 \AA$ and $92.27^{\circ}$. The determined $r_{\mathrm{e}}$ and $\theta_{\mathrm{e}}$ for the $\tilde{A}^{1} \mathrm{~B}_{1}$ state are $1.4853(5) \AA$ and $122.48(8)^{\circ}$, which compares to the most recent wavefunction-based prediction ${ }^{45}$ of $1.4904 \AA$ and $122.70^{\circ}$. Other recent high-level multireference wavefunction calculations ${ }^{42}$ give $r_{\mathrm{e}}$ and $\theta_{\mathrm{e}}$ values for the $\tilde{X}^{1} \mathrm{~A}_{1}$ state that range from $1.5112 \AA$ to $1.5171 \AA$ and $92.52^{\circ}$ to $92.84^{\circ}$, and for the excited $\tilde{A}^{1} \mathrm{~B}_{1}$ state that range from $1.4839 \AA$ to $1.4890 \AA$ and $121.68^{\circ}$ to $122.26^{\circ}$ depending upon the basis set employed.

\section{CONCLUSION}

The LIF spectrum of the $0_{0}^{0} \tilde{X}^{1} \mathrm{~A}^{\prime} \rightarrow \tilde{A}^{1} \mathrm{~A}^{\prime \prime}$ band of a cold sample of SiHD has been analyzed and combined with existing data for $\mathrm{SiH}_{2}$ and $\mathrm{SiD}_{2}$ to produce an experimentally determined structure. The LIF spectrum of $\mathrm{SiHD}$ is significantly more complex than that of either $\mathrm{SiH}_{2}$ or $\mathrm{SiD}_{2}$ mainly due to the presence of axis-switching induced transitions. The observed relative intensities of the axis-switching transitions have been successfully modeled. The inertial defects in the $\tilde{X}^{1} \mathrm{~A}_{1}$ states of $\mathrm{SiH}_{2}$ and $\mathrm{SiD}_{2}$ and the $\tilde{X}^{1} \mathrm{~A}^{\prime}$ state of SiHD have been successfully modelled assuming a dominant vibronic contribution, whereas those for the excited state are inconsistent with such a model. Similar to $\mathrm{SiH}_{2}$ and $\mathrm{SiD}_{2}$, the fluorescence lifetimes rapidly decrease as a function of $K_{\mathrm{a}}$ from a nominal value of $1 \mu \mathrm{s}$ for the $0_{00}$ level. The analysis of the optical spectrum of SiHD performed here will be relevant to future experimental and theoretical investigations of unimolecular dynamics. Optical Stark spectroscopic studies of SiHD based upon the observations presented here are being pursued in our laboratory. The determined ground state rotational parameters for SiHD will facilitate laboratory and radio telescope searches for the $a$-type ( $\Delta K_{\mathrm{a}}=$ even, $\Delta K_{\mathrm{c}}=$ odd) and $b$-type $\left(\Delta K_{\mathrm{a}}=\right.$ odd, $\Delta K_{\mathrm{c}}=$ odd $)$ pure rotational transitions.

\section{ACKNOWLEDGMENTS}

This research has been supported by the National Science Foundation, Division of Chemistry, CHE-1265885 (ASU).

\section{APPENDIX: RELATIVE INTENSITIES AND ECKART AXES}

The objective is to predict the relative intensities when the effects of axis switching are considered. The $3 \times 3$ rotation matrix, $\mathbf{T}$, associated with the $0_{0}^{0} \tilde{X}^{1} \mathrm{~A}^{\prime} \rightarrow \tilde{A}^{1} \mathrm{~A}^{\prime \prime}$ transition is defined by Eckart conditions, ${ }^{55}$

$$
\sum_{\alpha} m_{\alpha}\left(\mathbf{T} \cdot \mathbf{r}_{\alpha}^{0}(\tilde{X})\right) \times\left(\boldsymbol{\rho}_{\alpha}(\tilde{A})+\mathbf{r}_{\alpha}^{0}(\tilde{A})\right)=0
$$

where $\mathbf{r}_{\alpha}^{0}(\tilde{X})$ and $\mathbf{r}_{\alpha}^{0}(\tilde{A})$ are the equilibrium position of the $\alpha$-th nuclei having mass $m_{\alpha}$ in the $\tilde{X}^{1} \mathrm{~A}^{\prime}$ and $A^{1} \mathrm{~A}^{\prime \prime}$ electronic state. $\rho_{\alpha}(\tilde{A})$ is the Cartesian displacement vector of the $\alpha$-th nuclei in the $A^{1} \mathrm{~A}^{\prime \prime}$ electronic state. For strongly bound molecules with low vibrational excitation, the displacement vectors are small. Under these circumstances, it is often possible to use the "zeroth order axis switching" method ${ }^{53,55}$ that assumes that $\boldsymbol{\rho}_{\alpha}(\tilde{A})=0$, in which case $\mathbf{T}\left(\boldsymbol{\rho}_{\alpha}(\tilde{A})=0\right) \equiv \mathbf{T}_{0}$. The rotation matrix $\mathbf{T}_{0}$ depends upon the equilibria location of the nuclei in the principal axes for the $A^{1} \mathrm{~A}^{\prime \prime}$ and $\tilde{X}^{1} \mathrm{~A}^{\prime}$ states, which are given in Figure 6. Under the "zeroth order axis switching" assumption, the Eckart conditions (Eq. (A1) gives

$$
\mathbf{T}_{0}=\left[\begin{array}{ccc}
\cos \Omega_{0} & \sin \Omega_{0} & 0 \\
-\sin \Omega_{0} & \cos \Omega_{0} & 0 \\
0 & 0 & 1
\end{array}\right]
$$

where the rotation angle $\Omega_{0}$ is defined by ${ }^{55}$

$$
\tan \Omega_{0}=\frac{\sum_{\alpha} \mathrm{m}_{\alpha}\left(a_{\alpha}^{\circ}(\tilde{X}) b_{\alpha}^{\circ}(\tilde{A})-b_{\alpha}^{\circ}(\tilde{X}) \mathrm{a}_{\alpha}^{\circ}(\tilde{A})\right)}{\sum_{\alpha} \mathrm{m}_{\alpha}\left(a_{\alpha}^{\circ}(\tilde{X}) \mathrm{a}_{\alpha}^{\circ}(\tilde{A})+\mathrm{b}_{\alpha}^{\circ}(\tilde{X}) b_{\alpha}^{\circ}(\tilde{A})\right)} .
$$

In Eq. (A3), $a_{\alpha}^{\circ}(\tilde{X})$ is the $a$-principal axis location of the $\alpha$-th nuclei in the $\tilde{X}^{1} \mathrm{~A}^{\prime}$ electronic state and $b_{\alpha}^{\circ}(\tilde{A})$ is the $b$-principal axis location of the $\alpha$-th nuclei in the $A^{1} \mathrm{~A}^{\prime \prime}$ electronic state. A rotation angle, $\Omega_{0}$, of $21.7^{\circ}$ is predicted using the $a$-principal axis and $b$-principal axis coordinates shown in Figure 6 . The angles $\theta_{\mathrm{A}}$ and $\theta_{\mathrm{X}}$ shown in Figure 6 are of orientation of the $\mathrm{Si}-\mathrm{D}$ bond relative to the $a$-principal axis for the $A^{1} \mathrm{~A}^{\prime \prime}$ and $\tilde{X}^{1} \mathrm{~A}^{\prime}$ states, respectively. The relative orientation of the $\mathrm{H}$, $\mathrm{D}$, and Si nuclei in the principal axes of the $\tilde{X}^{1} \mathrm{~A}^{\prime}$ and $A^{1} \mathrm{~A}^{\prime \prime}$ states, as well as that for the $A^{1} \mathrm{~A}^{\prime \prime}$ state in an Eckart axes, is given in Figure 7 . Note that the $21.7^{\circ}$ rotation of the principal axis of the $A^{1} \mathrm{~A}^{\prime \prime}$ state produces an orientation in the Eckart axis that approximately achieves a mass-weighted shift of the $\mathrm{H}$ and $\mathrm{D}$ nuclei relative to that of the $\tilde{X}^{1} \mathrm{~A}^{\prime}$ state. Also note that $\Omega^{*}=\Omega_{0}+\left(\theta_{\mathrm{A}}-\theta_{\mathrm{X}}\right)$, where $\Omega^{*}$ is the angle between the $A^{1} \mathrm{~A}^{\prime \prime}$ state structure in an Eckart axes and the $\tilde{X}^{1} \mathrm{~A}^{\prime}$ structure in the principal axis system when the two systems are made to be coincident (see Figure 7). 
The inertial tensor, $\mathbf{I}$, for the $A^{1} \mathrm{~A}^{\prime \prime}$ state expressed in the Eckart axis system is (amu $\AA$ ) ,

$$
\mathbf{I}=\left[\begin{array}{ccc}
1.761 & -1.390 & 0 \\
-1.390 & 4.698 & 0 \\
0 & 0 & 6.458
\end{array}\right]
$$

Taking the inverse of $\mathbf{I}$ and multiplying by the appropriate constant gives the rotational Cartesian tensor (in $\mathrm{cm}^{-1}$ ),

$$
\underline{\underline{\mathbf{B}}}=\left[\begin{array}{ccc}
12.496 & 3.698 & 0 \\
3.698 & 4.683 & 0 \\
0 & 0 & 2.601
\end{array}\right] .
$$

It is convenient to write the matrix elements of $\mathrm{H}^{\text {rot }}$ $(=\hat{\mathrm{J}} \times \underline{\mathrm{B}} \times \hat{\mathrm{J}})$ in spherical tensor form and express these elements in a type $\mathrm{I}^{\mathrm{r}}$ convention axis system ${ }^{70}$ (i.e., a right handed system with the $a$-principal axis $=$ molecular fixed $z$-axis) prolate symmetric top basis set,

$$
\begin{aligned}
\left\langle J^{\prime}, k_{a}{ }^{\prime}\left|\hat{\mathrm{H}}^{\mathrm{rot}}\right| J, K_{\mathrm{a}}\right\rangle= & \delta_{J, J^{\prime}}(-1)^{J^{\prime}-k^{\prime}}((2 J+1)(J+1) J) \\
& \times \sum_{\mathrm{k}=0}^{2}(-1)^{\mathrm{k}}(2 \mathrm{k}+1)^{1 / 2}\left\{\begin{array}{ccc}
1 & \mathrm{k} & 1 \\
J & J & J
\end{array}\right\} \\
& \times\left(\begin{array}{ccc}
J & \mathrm{k} & J \\
-k_{\mathrm{a}}^{\prime} & k_{\mathrm{a}}^{\prime}-\mathrm{q} & k_{\mathrm{a}}
\end{array}\right) \mathrm{T}_{\mathrm{q}}^{\mathrm{k}}(\mathrm{B}) .
\end{aligned}
$$

In Eq. (A6), $k_{\mathrm{a}}$ is the projection of the rotational angular momentum on the $a$-principal axis system and $\mathrm{T}_{\mathrm{q}}^{\mathrm{k}=0,1,2}(\mathrm{~B})$ are the molecular fixed axis spherical tensor components of the rotational constant tensor $\underline{\underline{B}}$. The non-zero values of $\mathrm{T}_{\mathrm{q}}^{\mathrm{k}=0,1,2}(\mathrm{~B})$ are

$$
\begin{gathered}
\mathrm{T}_{0}^{0}(\mathrm{~B})=-\frac{1}{\sqrt{3}}(A+B+C), \\
\mathrm{T}_{0}^{2}(\mathrm{~B})=\frac{1}{\sqrt{6}}(2 A-B-C), \\
\mathrm{T}_{ \pm 2}^{2}(\mathrm{~B})=\frac{1}{2}(B-i C), \\
\mathrm{T}_{ \pm 1}^{2}(\mathrm{~B})=\mp D .
\end{gathered}
$$

It is evident from the $3 \mathrm{j}$-symbol in Eq. (A6) that the off-diagonal term, $D$, produces a $\Delta k_{\mathrm{a}}= \pm 1$ mixing of prolate symmetric top basis functions. As a consequence, in addition to the "perpendicular," $c$-type $\left(\Delta J=0, \pm 1, \Delta K_{a}\right.$ $\left.= \pm 1, \pm 3 \ldots \Delta K_{\mathrm{c}}=0, \pm 2, \ldots\right)$ transitions, there are "parallel" $\Delta J=0, \pm 1, \Delta K_{\mathrm{a}}=0, \pm 2$ transitions. The mixing of prolate symmetric top basis functions, and hence the intensities of the axis-switching induced transitions, is relatively large due to the relatively large value $D$. For example, the eigenvector for the $\left|1_{11}\right\rangle$ rotational level of the $A^{1} \mathrm{~A}^{\prime \prime}$ state in the principal axis system is

$\left|1_{11}\right\rangle=\frac{1}{\sqrt{2}}\left[\left|J=1, k_{\mathrm{a}}=+1\right\rangle-\left|J=1, k_{\mathrm{a}}=-1\right\rangle\right]$,

whereas in the Eckart axis system it is

$$
\begin{aligned}
\left|1_{11}\right\rangle= & \mathrm{c}_{1}\left|J=1, k_{\mathrm{a}}=+1\right\rangle-\mathrm{c}_{1}\left|J=1, k_{\mathrm{a}}=-1\right\rangle \\
& +c_{2}\left|J=1, k_{\mathrm{a}}=0\right\rangle,
\end{aligned}
$$

with $\mathrm{c}_{1}=0.657$ and $\mathrm{c}_{2}=0.370$.
${ }^{1}$ S. Cereda, F. Montalenti, M. Cogoni, D. Branduardi, M. W. Radny, P. V. Smith, and L. Miglio, Surf. Sci. 600(19), 4445-4453 (2006).

${ }^{2}$ N. Reuge and B. Caussat, Chem. Vap. Deposition 17(10-12), 305-311 (2011).

${ }^{3}$ P. Raghunath and M. C. Lin, J. Phys. Chem. A 117(42), 10811-10823 (2013).

${ }^{4}$ T. Kuwahara, H. Ito, K. Kawaguchi, Y. Higuchi, N. Ozawa, and M. Kubo, J. Phys. Chem. C 117(30), 15602-15614 (2013).

${ }^{5}$ H.-T. Chen and H.-W. Huang, J. Phys. Chem. C 118(35), 20314-20322 (2014).

${ }^{6}$ S. Cereda, F. Montalenti, and L. Miglio, Surf. Sci. 601(18), 3970-3973 (2007)

${ }^{7}$ I. Dubois, G. Herzberg, and R. D. Verma, J. Chem. Phys. 47(10), 4262-4263 (1967).

${ }^{8}$ I. Dubois, Can. J. Phys. 46(22), 2485-2490 (1968).

${ }^{9}$ I. Dubois, G. Duxbury, and R. N. Dixon, J. Chem. Soc., Faraday Trans. 2 71(4), 799-806 (1975).

${ }^{10}$ G. Inoue and M. Suzuki, Chem. Phys. Lett. 105(6), 641-644 (1984).

${ }^{11}$ J. W. Thoman, Jr. and J. I. Steinfeld, Chem. Phys. Lett. 124(1), 35-38 (1986).

12J. J. O'Brien and G. H. Atkinson, Chem. Phys. Lett. 130(4), 321-329 (1986).

${ }^{13}$ Y. M. Engel, R. D. Levine, J. W. Thoman, Jr., J. I. Steinfeld, and R. I. McKay, J. Chem. Phys. 86(11), 6561-6563 (1987).

${ }^{14}$ J. W. Thoman, Jr., J. I. Steinfeld, R. I. McKay, and A. E. W. Knight, J. Chem. Phys. 86(11), 5909-5917 (1987).

${ }^{15}$ J. S. Francisco, R. Barnes, and J. W. Thoman, Jr., J. Chem. Phys. 88(4), 2334-2341 (1988).

${ }^{16}$ J. Berkowitz, J. P. Greene, H. Cho, and B. Ruscic, J. Chem. Phys. 86(3), 1235-1248 (1987).

${ }^{17}$ C. Yamada, H. Kanamori, E. Hirota, N. Nishiwaki, N. Itabashi, K. Kato, and T. Goto, J. Chem. Phys. 91(8), 4582-4586 (1989).

${ }^{18}$ M. Fukushima, S. Mayama, and K. Obi, J. Chem. Phys. 96(1), 44-52 (1992).

${ }^{19}$ M. Fukushima and K. Obi, J. Chem. Phys. 100(9), 6221-6227 (1994).

${ }^{20} \mathrm{H}$. Ishikawa and O. Kajimoto, J. Mol. Spectrosc. 160(1), 1-10 (1993).

${ }^{21}$ A. Kono, N. Koike, H. Nomura, and T. Goto, Jpn. J. Appl. Phys., Part 1 34(1), 307-311 (1995).

${ }^{22}$ N. M. Rubtsov, V. V. Azatyan, G. I. Tsvetkov, and S. M. Temchin, Mendeleev Commun. 7(5), 187-188 (1997).

${ }^{23}$ A. Kono, S. Hirose, K. Kinoshita, and T. Goto, Jpn. J. Appl. Phys., Part 1 37(8), 4588-4589 (1998).

${ }^{24}$ A. Campargue, D. Romanini, and N. Sadeghi, J. Phys. D: Appl. Phys. 31(10), 1168-1175 (1998).

${ }^{25}$ R. Escribano and A. Campargue, J. Chem. Phys. 108(15), 6249-6257 (1998).

${ }^{26}$ E. Hirota and H. Ishikawa, J. Chem. Phys. 110(9), 4254-4257 (1999).

${ }^{27}$ H. Ishikawa, Y. Muramoto, and N. Mikami, J. Mol. Spectrosc. 216(1), 90-97 (2002).

${ }^{28}$ Y. Muramoto, H. Ishikawa, and N. Mikami, J. Chem. Phys. 122(15), 154302 (2005).

${ }^{29}$ M. E. Colvin, R. S. Grev, H. F. Schaeffer III, and J. Bicerano, Chem. Phys. Lett. 99(5-6), 399-405 (1983).

${ }^{30}$ J. E. Rice and N. C. Handy, Chem. Phys. Lett. 107(4-5), 365-374 (1984).

${ }^{31}$ M. S. Gordon, Chem. Phys. Lett. 114(4), 348-352 (1985).

${ }^{32}$ W. D. Allen and H. F. Schaefer III, Chem. Phys. 108(2), 243-274 (1986).

${ }^{33}$ K. Balasubramanian and A. D. McLean, J. Chem. Phys. 85(9), 5117-5119 (1986).

${ }^{34}$ C. W. Bauschlicher, Jr., S. R. Langhoff, and P. R. Taylor, J. Chem. Phys. 87(1), 387-391 (1987).

${ }^{35}$ C. W. Bauschlicher, Jr. and P. R. Taylor, J. Chem. Phys. 86(3), 1420-1424 (1987).

${ }^{36}$ S. Koseki and M. S. Gordon, J. Mol. Spectrosc. 123(2), 392-404 (1987).

${ }^{37}$ W. Gabriel, P. Rosmus, K. Yamashita, K. Morokuma, and P. Palmieri, Chem. Phys. 174(1), 45-56 (1993).

${ }^{38}$ G. Duxbury, A. Alijah, and R. R. Trieling, J. Chem. Phys. 98(2), 811-825 (1993).

${ }^{39}$ Y. Yamaguchi, T. J. Van Huis, C. D. Sherill, and H. F. Schaefer III, Theor. Chem. Acc. 97(1-4), 341-349 (1997).

${ }^{40}$ L. V. Slipchenko and A. I. Krylov, J. Chem. Phys. 117(10), 4694-4708 (2002).

${ }^{41}$ Y. Apeloig, R. Pauncz, M. Karni, R. West, W. Steiner, and D. Chapman, Organometallics 22(16), 3250-3256 (2003).

${ }^{42}$ A. Kalemos, T. H. Dunning, Jr., and A. Mavridis, Mol. Phys. 102(23-24), 2597-2606 (2004). 
${ }^{43}$ S. N. Yurchenko, P. R. Bunker, W. P. Kraemer, and P. Jensen, Can. J. Chem. 82(6), 694-708 (2004).

${ }^{44}$ R. Guerout, P. R. Bunker, P. Jensen, and W. P. Kraemer, J. Chem. Phys. 123(24), 244312 (2005).

${ }^{45}$ I. Tokue, K. Yamasaki, and S. Nanbu, J. Chem. Phys. 122(14), 144307 (2005).

${ }^{46}$ I. Tokue, K. Yamasaki, and S. Nanbu, J. Chem. Phys. 124(11), 114308 (2006).

${ }^{47}$ Y. A. Bernard, Y. Shao, and A. I. Krylov, J. Chem. Phys. 136(20), 204103 (2012).

${ }^{48}$ R. R. Zaari and S. A. Varganov, J. Phys. Chem. A 119(8), 1332-1338 (2015).

${ }^{49}$ D. D. S. MacKay and S. B. Charnley, Mon. Not. R. Astron. Soc. 302(4), 793-800 (1999).

${ }^{50}$ B. E. Turner, Astrophys. J. 388(1, Pt. 2), L35-L38 (1992).

${ }^{51}$ L. W. Avery, M. B. Bell, C. T. Cunningham, P. A. Feldman, R. H. Hayward, J. M. MacLeod, H. E. Matthews, and J. D. Wade, Astrophys. J. 426(2, Pt. 1), 737-741 (1994).

${ }^{52}$ L. Fredin, R. H. Hauge, Z. H. Kafafi, and J. L. Margrave, J. Chem. Phys. 82(8), 3542-3545 (1985).

${ }^{53}$ J. T. Hougen and J. K. G. Watson, Can. J. Phys. 43(2), 298-320 (1965).

${ }^{54}$ J. M. Brown and D. A. Ramsay, Can. J. Phys. 53(19), 2232-2241 (1975).

${ }^{55}$ I. Ozkan, J. Mol. Spectrosc. 139(1), 147-162 (1990).

${ }^{56}$ D. M. Jonas, X. Yang, and A. M. Wodtke, J. Chem. Phys. 97(4), 2284-2298 (1992).

${ }^{57}$ A. Lin, K. Kobayashi, H.-G. Yu, G. E. Hall, J. T. Muckerman, T. J. Sears, and A. J. Merer, J. Mol. Spectrosc. 214(2), 216-224 (2002).

${ }^{58}$ P. Dupre, J. Chem. Phys. 134(24), 244309 (2011).

${ }^{59}$ T. C. Steimle, F. Wang, X. Zhuang, and Z. Wang, J. Chem. Phys. 136(11), 114309 (2012).

${ }^{60}$ N. J. Reilly, T. W. Schmidt, and S. H. Kable, J. Phys. Chem. A 110(45), 12355-12359 (2006)

${ }^{61}$ J. R. Gascooke, U. N. Alexander, and W. D. Lawrance, J. Chem. Phys. 134(18), 184301 (2011).

${ }^{62}$ D. L. Kokkin, T. C. Steimle, and D. DeMille, Phys. Rev. A: At., Mol., Opt. Phys. 90(6-A), 062503 (2014).

${ }^{63}$ E. J. Salumbides, K. S. E. Eikema, W. Ubachs, U. Hollenstein, H. Knoeckel, and E. Tiemann, Mol. Phys. 104(16-17), 2641-2652 (2006).
${ }^{64}$ K. S. Ojha and R. Gopal, Spectrochim. Acta, Part A 71A(3), 1003-1006 (2008).

${ }^{65}$ H. Ishikawa and O. Kajimoto, J. Mol. Spectrosc. 174(1), 270-273 (1995).

${ }^{66}$ P. R. Bunker and P. Jensen, Molecular Symmetry and Spectroscopy, 2nd ed. (NRCC, 1998)

${ }^{67}$ V. Szalay, J. Chem. Phys. 140(23), 234107 (2014).

${ }^{68}$ T. Oka and Y. Morino, J. Mol. Spectrosc. 6, 472-482 (1961).

${ }^{69}$ T. Oka and Y. Morino, J. Mol. Spectrosc. 8, 9-21 (1962).

${ }^{70} \mathrm{~W}$. Gordy and R. L. Cook, Microwave Molecular Spectra, Techniques of Chemistry Vol. 56 (John Wiley and Sons, 1984).

${ }^{71}$ C. Lee, W. Yang, and R. G. Parr, Phys. Rev. B: Condens. Matter 37(2), 785-789 (1988).

${ }^{72}$ E. Runge and E. K. U. Gross, Phys. Rev. Lett. 52(12), 997-1000 (1984).

${ }^{73}$ A. D. Becke, J. Chem. Phys. 98(7), 5648-5652 (1993).

${ }^{74}$ M. J. Frisch, G. W. Trucks, H. B. Schlegel, G. E. Scuseria, M. A. Robb, J. R. Cheeseman, J. A. Montgomery, Jr., T. Vreven, K. N. Kudin, J. C. Burant, J. M. Millam, S. S. Iyengar, J. Tomasi, V. Barone, B. Mennucci, M. Cossi, G. Scalmani, N. Rega, G. A. Petersson, H. Nakatsuji, M. Hada, M. Ehara, K. Toyota, R. Fukuda, J. Hasegawa, M. Ishida, T. Nakajima, Y. Honda, O. Kitao, H. Nakai, M. Klene, X. Li, J. E. Knox, H. P. Hratchian, J. B. Cross, V. Bakken, C. Adamo, J. Jaramillo, R. Gomperts, R. E. Stratmann, O. Yazyev, A. J. Austin, R. Cammi, C. Pomelli, J. W. Ochterski, P. Y. Ayala, K. Morokuma, G. A. Voth, P. Salvador, J. J. Dannenberg, V. G. Zakrzewski, S. Dapprich, A. D. Daniels, M. C. Strain, O. Farkas, D. K. Malick, A. D. Rabuck, K. Raghavachari, J. B. Foresman, J. V. Ortiz, Q. Cui, A. G. Baboul, S. Clifford, J. Cioslowski, B. B. Stefanov, G. Liu, A. Liashenko, P. Piskorz, I. Komaromi, R. L. Martin, D. J. Fox, T. Keith, M. A. Al-Laham, C. Y. Peng, A. Nanayakkara, M. Challacombe, P. M. W. Gill, B. Johnson, W. Chen, M. W. Wong, C. Gonzalez, and J. A. Pople, Gaussian 03, Revision C.02 (Gaussian, Inc., Wallingford, CT, 2004).

${ }^{75}$ See supplementary material at http://dx.doi.org/10.1063/1.4954702 for tables of: (a) the calculated ground state vibration rotation parameters, experimental and equilibrium rotational constants; (b) calculated excited state vibration rotation parameters, experimental and equilibrium rotational constants, and (c) calculated harmonic frequencies $\left(\mathrm{cm}^{-1}\right)$ and Coriolis constants.

${ }^{76}$ Z. Kisiel, J. Mol. Spectrosc. 218(1), 58-67 (2003). 